\title{
Novel hybrid process for the conversion of microcrystalline cellulose to value-added chemicals: part 1: process optimization
}

\author{
Okan Akin · Asli Yuksel
}

Received: 31 May 2016/Accepted: 25 August 2016/Published online: 30 August 2016

(C) Springer Science+Business Media Dordrecht 2016

\begin{abstract}
In this paper, a novel hybrid process for the treatment of microcrystalline cellulose (MCC) under hot-compressed water was investigated by applying constant direct current on the reaction medium. Constant current range from $1 \mathrm{~A}$ to $2 \mathrm{~A}$ was applied through a cylindrical anode made of titanium to the reactor wall. Reactions were conducted using a specially designed batch reactor $(450 \mathrm{~mL})$ made of SUS 316 stainless steel for 30-120 min of reaction time at temperature range of $170-230{ }^{\circ} \mathrm{C}$. As a proton donor $\mathrm{H}_{2} \mathrm{SO}_{4}$ was used at concentrations of $1-50 \mathrm{mM}$. Main hydrolysis products of MCC degradation in $\mathrm{HCW}$ were detected as glucose, fructose, levulinic acid, 5-HMF, and furfural. For the quantification of these products, High Performance Liquid Chromatography (HPLC) and Gas Chromatography with Mass Spectroscopy (GC-MS) were used. A $1 / 2$ fractional factorial design with 2-level of four factors; reaction time, temperature, $\mathrm{H}_{2} \mathrm{SO}_{4}$ concentration and applied current with 3 center points were built and responses were statistically analyzed. Response surface methodology was used for process optimization and it was found that introduction of $1 \mathrm{~A}$ current at $200{ }^{\circ} \mathrm{C}$ to the
\end{abstract}

Electronic supplementary material The online version of this article (doi:10.1007/s10570-016-1054-3) contains supplementary material, which is available to authorized users.

O. Akin · A. Yuksel $(\bowtie)$

Chemical Engineering Department, İzmir Institute of

Technology, Urla, Izmir 35430, Turkey

e-mail: asliyuksel@iyte.edu.tr reaction medium increased Total Organic Carbon (TOC) and cellulose conversions to 62 and $81 \%$, respectively. Moreover, application of current diminished the necessary reaction temperature and time to obtain high TOC and cellulose conversion values and hence decreased the energy required for cellulose hydrolysis to value added chemicals. Applied current had diverse effect on levulinic acid concentration $(29.9 \%)$ in the liquid product $\left(230{ }^{\circ} \mathrm{C}, 120 \mathrm{~min} ., 2 \mathrm{~A}\right.$, $50 \mathrm{mM} \mathrm{H}_{2} \mathrm{SO}_{4}$ ).

Keywords Biomass - Cellulose $\cdot$ Levulinic acid · 5HMF $\cdot$ Sub-critical water $\cdot$ Hydrothermal electrolysis

\section{Introduction}

The growing interest in biomass as renewable feedstock for the production of value-added products results not only from environmental concerns but also from the need for political stability, which play an important role. With the uncertainties of petroleumbased economy, many nations have been transferring their petroleum-based economy to bio-based. Therefore, a nation lacking in of petroleum stocks can take advantage of its natural sources (biomass) to produce such value-added products as fermentable sugars and chemicals. In this manner, conversion of different kinds of biomass sources to high value-added chemicals has been investigated in literature for last decades 
(Wu et al. 2010; Yan et al. 2010). So far, mineral acids (Muranaka et al. 2014), solid acid catalysts (Liu et al. 2015; Zi et al. 2015), enzymes (Annamalai et al. 2014; Badgujar and Bhanage 2016), subcritical water (Saito et al. 2009) have been used to hydrolyze biomass into value-added chemicals such as Levulinic acid, Hydroxymethylfurfural (5-HMF), Furfural.

Sub- and super-critical water have gotten much attention due to the versatile properties such as dielectric constant $(\varepsilon \cong 10$ near critical) and the ion product concentration which is $10^{-11}$ in the temperature range between 200 and $300{ }^{\circ} \mathrm{C}$ (Marshall and Franck 1981). Increase in temperature leads to decrease in $\mathrm{pH}$ value of water by three units, providing more $\mathrm{H}_{3}{ }^{+}$ions for acid catalyzed reactions. Hence, the ionic product concentration can be used for optimizing acid-base reactions (Kruse and Dinjus 2007). In addition, the current efficiency increases at near critical conditions that result in more economically feasible electrochemical reactions (Asghari and Yoshida 2008). Due to these versatile properties of water at near critical region, electrolysis reaction of microcrystalline cellulose was conducted under hydrothermal conditions.

Treatments of cellulose in both hot compressed water and supercritical water have shown to be an efficient and environmentally friendly way to utilize cellulose for value-added chemicals (Kumar et al. 2011; Reddy et al. 2014). Reddy et al. (2014) showed that hydrolysis of cellulose at supercritical region favors the radical based reactions in which gaseous products as hydrogen and carbon dioxide were produced. Yin and Tan (2012) investigated cellulose hydrolysis at neutral, acidic, and alkaline mediums under hydrothermal conditions and found that reaction pathway changed in favor of 5-HMF and levulinic acid under acidic environment. However, 5-HMF polymerized to tarry materials at higher reaction temperature and longer time. Under alkaline condition, reaction favored the formation of carboxyl acids such as lactic and acetic acids. However, bio-oil yield could not exceed $35 \%$ under both acidic and alkaline environment. Therefore, parameters as reaction temperature, time and $\mathrm{pH}$ should not be separately investigated. Mante and Agblevor (2011) investigated the interaction parameters in pyrolysis of wood shavings and showed that liquid product yield is mainly influenced by temperature, feed rate and gas flow rate. Thus, in this study, hydrothermal electrolysis of cellulose was investigated by using factorial design to reveal interaction parameters between applied current, reaction temperature, time and acid concentration.

Electrochemical methods that are used for the oxidation and synthesis of organic compounds (Sasaki et al. 2007) have become attractive due to promising features that overcome the problems associated with conventional methods such as corrosion, long reaction times, and emission of greenhouse gases. As a hybrid technology, hot compressed water properties such as high ionic product concentration supply a high efficient medium in terms of migration of electroactive species. Thus, high current efficiency in electrochemical processes minimizes the amount of energy consumed for electrochemical reactions (Asghari and Yoshida 2008).

Studies on hydrothermal electrolysis of organic compounds (Sasaki et al. 2010; Yuksel et al. 2010) showed a promising method for the production of value added chemicals in terms of increased selectivity. Yuksel et al. (2010) studied electrolysis of glycerol in sub-critical water and reported that application of 1 A current to reaction medium increased the yield of lactic acid by $9 \%$ compared to experiments without current. Sasaki and coworkers (Sasaki et al. 2007) studied hydrothermal electrolysis of glucose and found that degradation products such as organic acids were produced with a yield of 40-60\%.

In this study, hydrothermal electrolysis of microcrystalline cellulose to value-added chemicals was investigated in detail and it was aimed to understand the effect of applied current on the product distribution, cellulose and TOC conversions. In this manner, product yields were statistically analyzed via Analysis of Variance (ANOVA) by considering interaction of applied current (0-2A) with other parameters such as $\mathrm{H}_{2} \mathrm{SO}_{4}$ concentration (1-50 mM), reaction temperature (170-230 ${ }^{\circ} \mathrm{C}$ ) and time (30-120 min.). Response surface methodology was used to optimize process parameters in a way of maximizing valuable products as levulinic acid, 5-HMF, and furfural.

\section{Materials and methods}

Microcrystalline cellulose (MCC, Sigma Aldrich) was used in powder form (particle size $<20 \mu \mathrm{m}$ ). Sulfuric Acid (Merck, 96-98\% purity) was used as eluent in HPLC (Agilent 1200). Analytical grade (>99\%, 
Fig. 1 a Hydrothermal electrolysis reactor: (1) electrical heater, (2) DC Power controller, (3) liquid sample tubing, (4) heat exchanger (5) gas sample collector, (6) anode, (7) rotor, (8) thermocouple, (9) pressure gauge, 10) sample holder, b Specially designed cylindrical electrode (anode) (a)

(b)

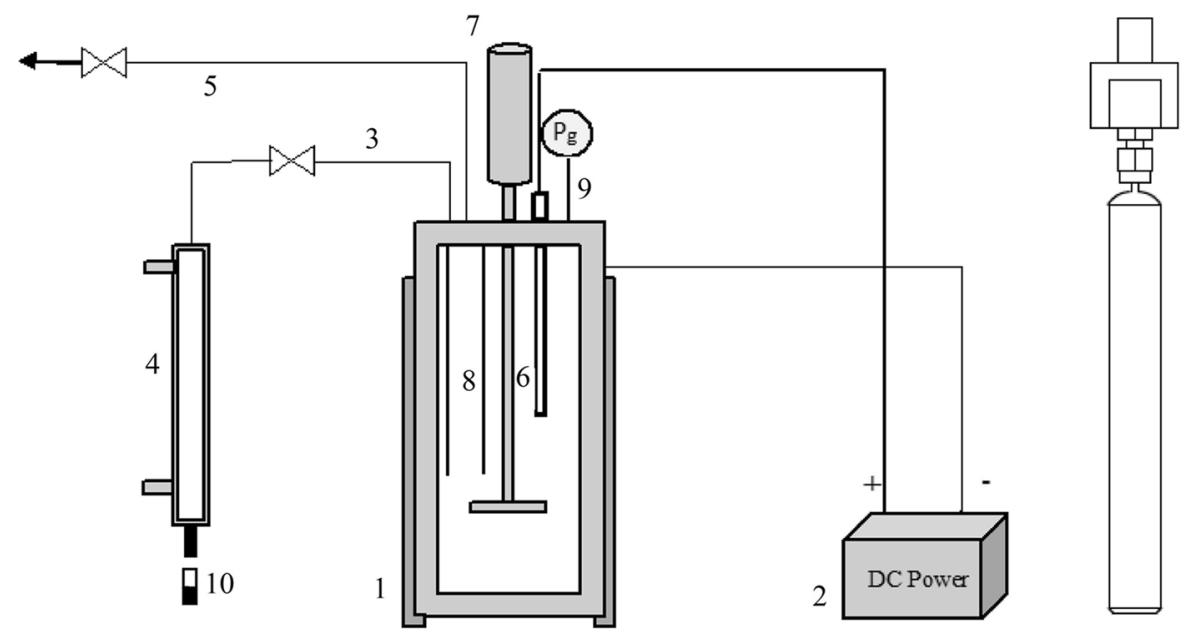

Sigma Aldrich) of standard chemicals as glucose, fructose, 5-HMF, levulinic acid, furfural, were used for the preparation of reference standards to build calibration curves for HPLC analysis to quantify the product yields.

In HPLC analysis, $3.75 \mathrm{mM} \mathrm{H}_{2} \mathrm{SO}_{4}$ with the flow rate of $0.5 \mathrm{ml} / \mathrm{min}$ was used as eluent. Sugar column (Shodex, SH1100) with column temperature of $50{ }^{\circ} \mathrm{C}$ was selected for clear separation of products. Refractive index (RID) was used for detection of aldehydes and organic acids. GC-MS (Agilent 6890 N/5973 N Network) was used to define the products that were unidentified in HPLC analyses. Gas products were analyzed by Gas Chromatography equipped with a Thermal Conductivity Detector (GC-TCD) (Agilent 6890 N). TOC analyzer (Shimadzu TOC- VCPH) was used to monitor TOC conversions in the liquid products and solid residues. Morphological properties of solid residues were analyzed by Scanning Electron Microscopy (SEM), (Quanta 250 SEM) with ETD detector. The chemical composition of solid residues obtained at the end of the reaction was analyzed by Fourier Transmission Infrared Spectroscopy (FT-IR). FT-IR analyses were conducted with scan rate of $4 \mathrm{~cm}^{-1}$ from $600-4000 \mathrm{~cm}^{-1}$ wavenumber by Perkin Elmer Frontier-Spectra two.

\section{Experimental procedure and equipment}

Hydrothermal electrolysis experiments were carried out in a $450 \mathrm{~mL}$ of batch reactor (Parr 5500 series) made of SUS 316 stainless steel, which is illustrated in Fig. 1. All experiments were conducted in $200 \mathrm{ml}$ of deionized water containing $8 \mathrm{gr}$ of cellulose. Sulfuric acid was added to the reaction medium as external proton source at different concentrations $(1-50 \mathrm{mM})$.

Reaction medium was heated to desired temperature with an external electrical heater and reaction time was set as zero when the desired reaction temperature is reached. In order to observe the effect of heating period, first sample was taken at the time of desired temperature is reached. $2 \mathrm{ml}$ of samples were collected at reaction times of $0,15,30,60,90$, and 120 min.

Hydrothermal electrolysis experiments were carried out at a constant current (0-2 A) passing through the electrodes. Specially designed cylindrical type electrode (12 mm diameter, $94 \mathrm{~mm}$ length), made of titanium, was used as anode and cylindrical reactor wall (165 $\mathrm{mm}$ in length, $76 \mathrm{~mm}$ outer diameter) was acted as cathode.

\section{Experimental design}

In this study, effect of parameters as reaction Current (A), Temperature (B), Time (C) and $\mathrm{H}_{2} \mathrm{SO}_{4}$ concentration (D) on responses such as conversion of cellulose, conversion of TOC, yields of 5-HMF, levulinic acid and furfural were statistically analyzed by using surface response methodology (RSM) to optimize desired responses. Experimental design was built by $1 / 2$ fractional factorials design with two level of 
Table 1 Experimental design and responses as percent yield of liquid products

\begin{tabular}{|c|c|c|c|c|c|c|c|c|c|c|c|}
\hline Design & $\begin{array}{l}\text { Temperature } \\
\left({ }^{\circ} \mathrm{C}\right)\end{array}$ & $\begin{array}{l}\text { Time } \\
\text { (min.) }\end{array}$ & $\begin{array}{l}\mathrm{H}_{2} \mathrm{SO}_{4} \\
(\mathrm{mM})\end{array}$ & $\begin{array}{l}\text { Current } \\
\text { (A) }\end{array}$ & Conversion & TOC & Glucose & Fructose & 5-HMF & Furfural & Levulinic acid \\
\hline- & 170 & 30 & 1 & 0 & 11.38 & 29.00 & 0.36 & 0.48 & 0.04 & 0.07 & 0.04 \\
\hline+-+ & 230 & 30 & 1 & 2 & 81.25 & 60.71 & 12.20 & 7.94 & 7.00 & 1.51 & 3.00 \\
\hline-+-+ & 170 & 120 & 1 & 2 & 11.25 & 8.10 & 1.71 & 1.94 & 0.18 & 0.16 & 0.68 \\
\hline++- & 230 & 120 & 1 & 0 & 70.63 & 40.48 & 8.47 & $*$ & 5.29 & 2.55 & 11.50 \\
\hline-++ & 170 & 30 & 50 & 2 & 29.00 & 22.00 & 4.17 & 3.21 & 0.74 & 0.35 & 1.57 \\
\hline+-+- & 230 & 30 & 50 & 0 & 77.13 & 61.50 & 4.64 & 1.74 & 3.57 & 2.20 & 36.00 \\
\hline-++- & 170 & 120 & 50 & 0 & 48.75 & 29.07 & 6.36 & 0.95 & 3.57 & 0.92 & 7.20 \\
\hline++++ & 230 & 120 & 50 & 2 & 74.38 & 39.38 & 0.60 & 0.24 & 0.27 & 0.48 & 28.98 \\
\hline-+ & 170 & 30 & 1 & 0 & 11.38 & 28.81 & 0.20 & 0.28 & 0.03 & 0.07 & 0.04 \\
\hline+-+ & 230 & 30 & 1 & 2 & 78.75 & 61.20 & 11.93 & 6.03 & 7.44 & 1.48 & 3.20 \\
\hline $0+-+$ & 170 & 120 & 1 & 2 & 7.50 & 8.21 & 1.58 & 1.90 & 0.17 & 0.13 & 0.50 \\
\hline++- & 230 & 120 & 1 & 0 & 68.75 & 41.00 & 9.00 & $*$ & 5.50 & 2.45 & 12.00 \\
\hline-++ & 170 & 30 & 50 & 2 & 30.75 & 22.35 & 4.20 & 3.69 & 0.96 & 0.48 & 1.40 \\
\hline+-+- & 230 & 30 & 50 & 0 & 82.63 & 62.02 & 4.63 & 2.85 & 2.82 & 2.43 & 37.00 \\
\hline-++- & 170 & 120 & 50 & 0 & 46.88 & 28.48 & 6.60 & 1.90 & 3.63 & 0.83 & 7.10 \\
\hline++++ & 230 & 120 & 50 & 2 & 77.00 & 39.52 & 0.44 & 0.26 & 0.35 & 0.47 & 29.90 \\
\hline 0000 & 200 & 75 & 25.5 & 1 & 81.13 & 62.62 & 15.41 & 7.79 & 3.71 & 1.05 & 12.44 \\
\hline 0000 & 200 & 75 & 25.5 & 1 & 81.38 & 62.20 & 15.70 & 7.20 & 3.50 & 1.04 & $*$ \\
\hline 0000 & 200 & 75 & 25.5 & 1 & 80.00 & 62.00 & 15.20 & 7.50 & 4.00 & 0.92 & 11.91 \\
\hline
\end{tabular}

* Data does not exist

(+) High, (0) Middle, (-) Low values of design variables

four factors (A, B, C, and D) with three center points and two replicates for corner points. A total number of 19 experimental runs were built and given in Table 1.

\section{Results and discussion}

HPLC and GC-MS analysis

Liquid products of cellulose decomposition contain variety of hydrocarbons. In this study, the key components of the reaction pathway such as glucose, fructose, levulinic acid, 5-HMF, and furfural were identified and quantified via HPLC (Fig. 2) and GCMS analyses. HPLC results were verified by GC-MS results of products point of interest (Table 2). In order to increase the sensitivity of GC-MS, Selected Ion Methodology (SIM) was used for the quantification of products.

Yield of product was calculated based on the carbon amount of species produced and initial amount of carbon in cellulose (Eq. 1). Carbon amount of cellulose was found as $42-45 \%$ by TOC analysis. For all experiments, carbon balance was calculated as above $90 \%$. Conversion of cellulose was calculated by using Eq. 2.

Yield of Product $\%=\frac{(\text { Number of carbon of species }) *(\text { Mole of species produced })}{\text { Moles of carbon in cellulose }} * 100$ 
Converted Cellulose $\%=\frac{\text { Initial amount of cellulose }(\mathrm{gram})-\text { Residual amount at the end }(\mathrm{gram})}{\text { Initial amount of cellulose }(\text { gram })} * 100$

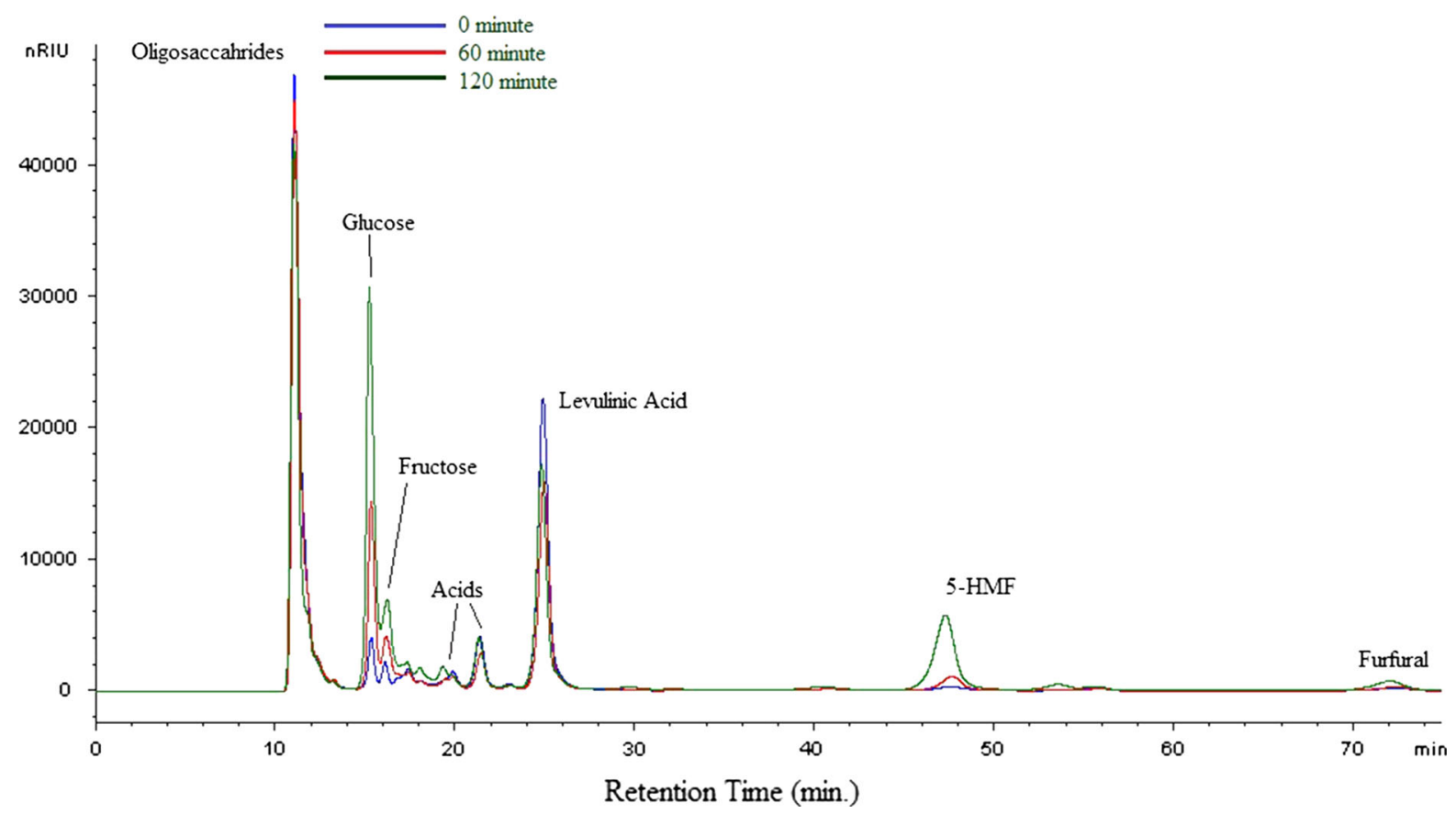

Fig. 2 HPLC chromatogram of cellulose decomposition products at $170{ }^{\circ} \mathrm{C}$, with $50 \mathrm{mM} \mathrm{H}_{2} \mathrm{SO}_{4}$ at sampling time of 0 , 60 and $120 \mathrm{~min}$

Table 2 GC-MS-SIM data of hydrolysis products of cellulose

\begin{tabular}{lll}
\hline Species & Molecule formula & Retention time (min.) \\
\hline Glyceraldehyde & $\mathrm{C}_{3} \mathrm{H}_{6} \mathrm{O}_{3}$ & 13.07 \\
Glycoaldehyde & $\mathrm{C}_{2} \mathrm{H}_{4} \mathrm{O}_{3}$ & 13.07 \\
Lactic acid & $\mathrm{C}_{3} \mathrm{H}_{6} \mathrm{O}_{3}$ & 29.72 \\
Glycerol & $\mathrm{C}_{3} \mathrm{H}_{8} \mathrm{O}_{3}$ & 31.29 \\
Formic acid & $\mathrm{CH}_{2} \mathrm{O}_{2}$ & 16.89 \\
Acetic acid & $\mathrm{C}_{2} \mathrm{H}_{4} \mathrm{O}_{2}$ & 15.1 \\
Levulinic acid & $\mathrm{C}_{5} \mathrm{H}_{8} \mathrm{O}_{3}$ & 31.62 \\
5-HMF & $\mathrm{C}_{6} \mathrm{H}_{6} \mathrm{O}_{3}$ & 36.09 \\
Furfural & $\mathrm{C}_{5} \mathrm{H}_{4} \mathrm{O}_{2}$ & 15.53 \\
\hline
\end{tabular}

Analyses of variance (ANOVA)

\section{Cellulose conversion}

Table 3 indicates summary of ANOVA test for cellulose conversion values. On this table,

p-values (less than $\alpha=0.05$ ) of each affecting parameters are given individually to consider the interactions between the parameters. The $\mathrm{R}^{2}$ with a value of 0.99 indicates that model is well fit to the observed response. The model accuracy is also confirmed by histograms including normal probability and residual plots. 
Table 3 Statistical analysis results for converted cellulose with $95 \%$ of confidence level

\begin{tabular}{lrrrrr}
\hline Source & DF & Sum of squares & Mean of squares & F value & $P$ value \\
\hline Model & 8.00 & 96.71 & 12.09 & 542.06 & 0.000 \\
Linear & 4.00 & 75.06 & 18.76 & 841.37 & 0.000 \\
Current & 1.00 & 0.31 & 0.31 & 13.69 & 0.004 \\
Temperature & 1.00 & 68.43 & 68.43 & 3068.57 & 0.000 \\
Time & 1.00 & 0.00 & 0.00 & 0.15 & 0.708 \\
$\mathrm{H}_{2} \mathrm{SO}_{4}$ & 1.00 & 6.31 & 6.31 & 283.06 & 0.000 \\
Square & 1.00 & 14.92 & 14.92 & 668.79 & 0.000 \\
Current $\times$ current & 1.00 & 14.92 & 14.92 & 668.79 & 0.000 \\
2-way interaction & 3.00 & 6.74 & 2.25 & 100.75 & 0.000 \\
Current $\times$ Temperature & 1.00 & 1.09 & 1.09 & 48.73 & 0.000 \\
Current $\times \mathrm{Time}_{\text {Time }}$ & 1.00 & 4.17 & 4.17 & 187.06 & 0.000 \\
Current $\times \mathrm{H}_{2} \mathrm{SO}_{4}$ & 1.00 & 1.48 & 1.48 & 66.47 & 0.000 \\
Error & 10.00 & 0.22 & 0.02 & & \\
Total & 18.00 & 96.93 & & & \\
\hline
\end{tabular}
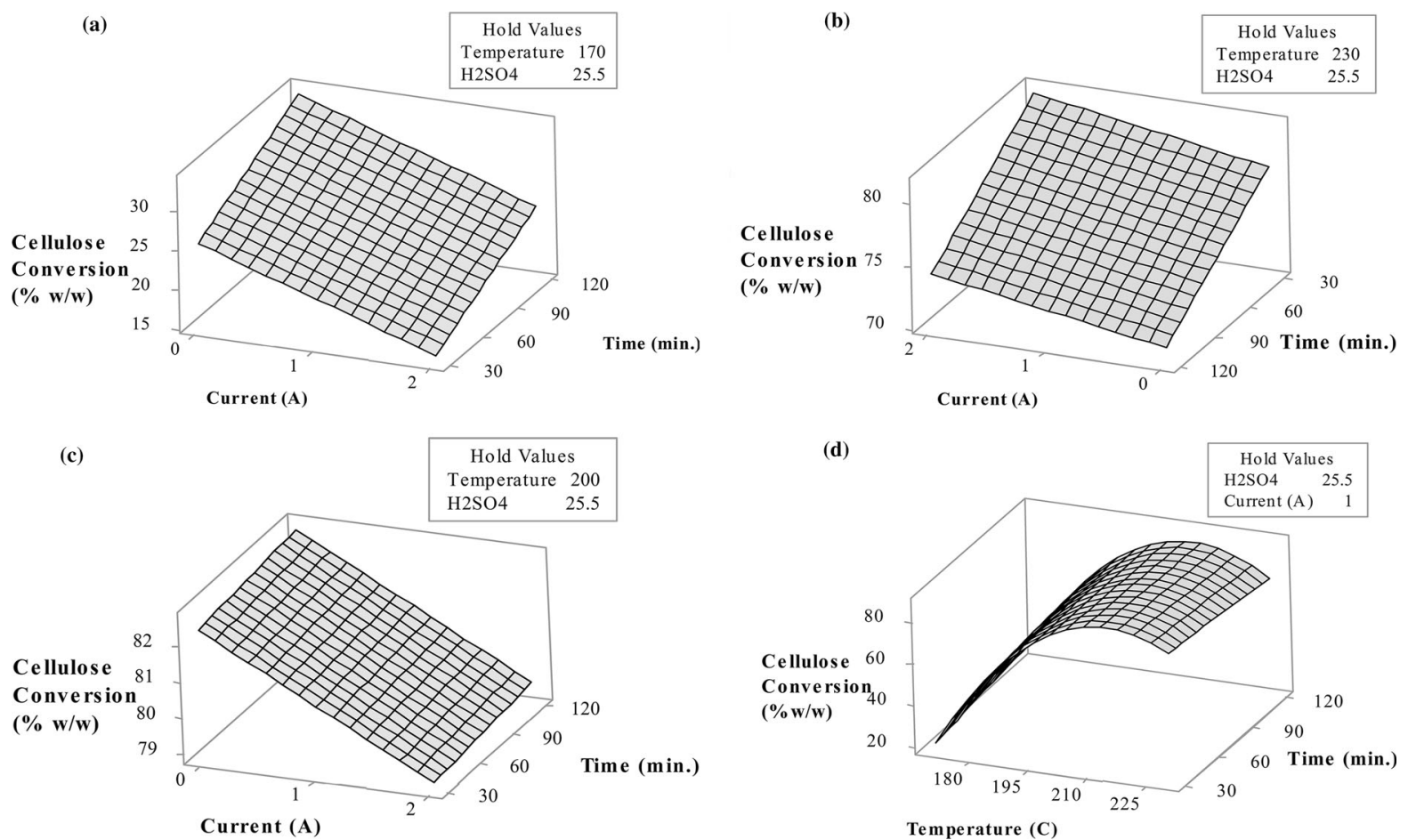

Fig. 3 Surface response plot of cellulose conversion with the hold values of $25 \mathrm{mM} \mathrm{H}_{2} \mathrm{SO}_{4}$ at a $170{ }^{\circ} \mathrm{C}$, b $230{ }^{\circ} \mathrm{C}$, c $200{ }^{\circ} \mathrm{C}$, and with d 1 A current

T-tests of operating parameters (current, temperature, $\mathrm{H}_{2} \mathrm{SO}_{4}$, time) defined the coefficient of main effects and their second orders with interaction terms in the model given as Eq. 3. The predicted cellulose conversion values can be found by using proposed model equation (Eq. 3) in the range of fitted boundaries. 
(a) Normal Probability Plot

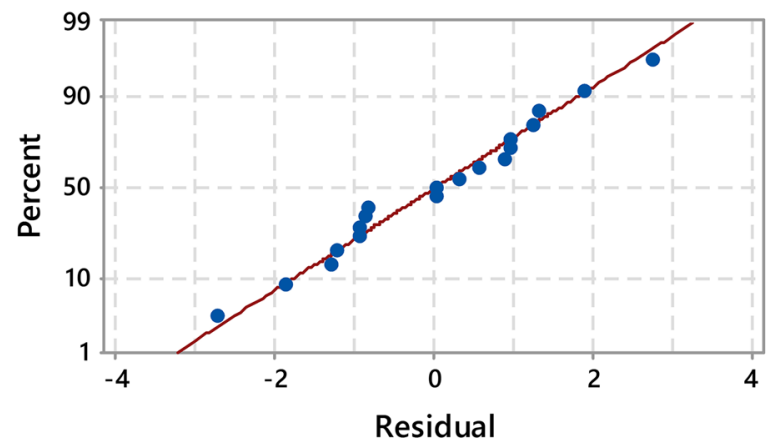

(c)

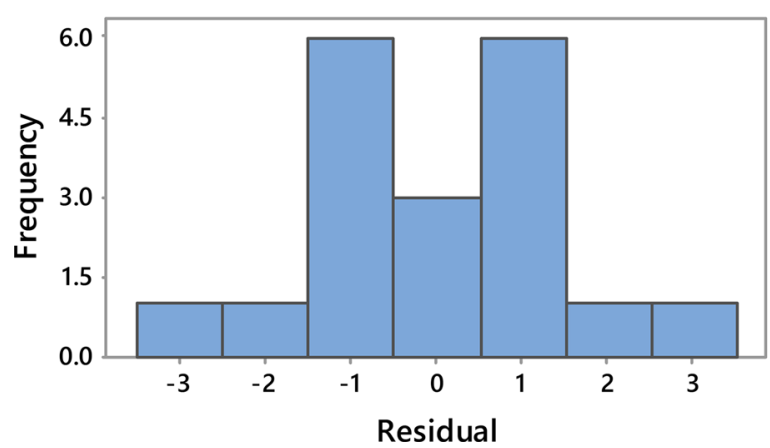

(b) Versus Fits

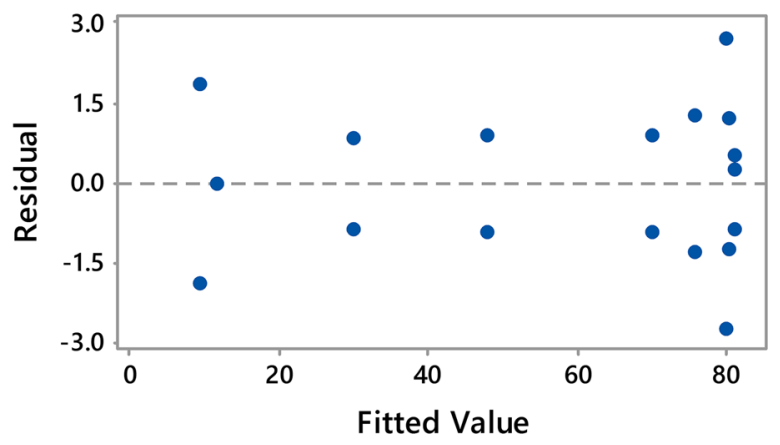

(d)

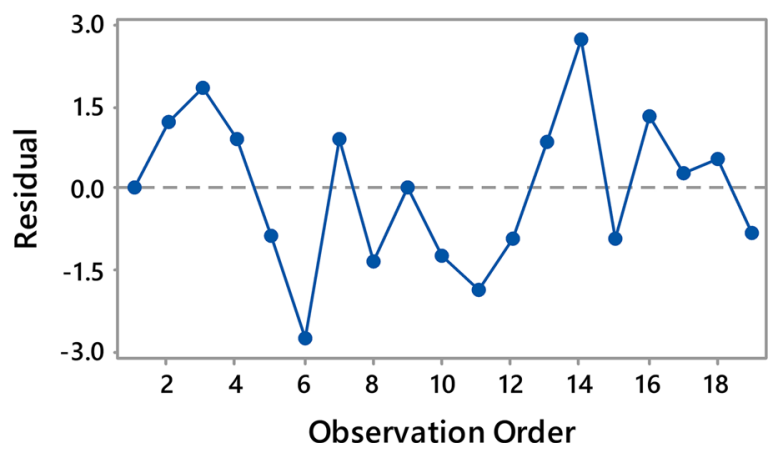

Fig. 4 Histogram plots of converted cellulose, a normal probability plot of residuals. b residuals versus predicted values, $\mathbf{c}$ frequency histogram of residuals, $\mathbf{d}$ observation orders of residuals

$$
\begin{aligned}
\text { Converted Cellulose }=- & 9.721+4.152 A+0.06025 B \\
& +0.01167 C+0.03806 D \\
& -2.4298 A^{2}+0.00869 A * B \\
& -0.011347 A * C \\
& -0.01242 A * D
\end{aligned}
$$

As seen in Table 3, in the model, some of the interaction terms were removed due to the lack of fit $(p>0.05)$ and considered as disturbance in the system causing error in the measured responses. As an individual parameter, reaction time has the $p$ value of 0.708 , which is higher than the confidence interval indicating that time has no significant effect on the conversion of cellulose. However, interaction parameter (current*time) showed that coupled effect of current and time was significant and thus, model did not avoid time as insignificant parameter. In order to visualize the effect of parameters, response surface plots (Fig. 1) of cellulose conversion was plotted by constant concentration of $25 \mathrm{mM} \mathrm{H}_{2} \mathrm{SO}_{4}$ at different reaction temperatures of 170,200 and $230{ }^{\circ} \mathrm{C}$. Temperature had the highest impact on cellulose degradation since temperature increases up to $220{ }^{\circ} \mathrm{C}$ as ionic product concentration increases in sub-critical water region (Dinjus and Kruse 2004). In order to depolymerize $\mathrm{MCC}$, hydronium ions $\left(\mathrm{H}_{3} \mathrm{O}^{+}\right)$must access to inter- or intra-molecular hydrogen bonding. Thus, diffusion of protons $\left(\mathrm{H}^{+}\right)$plays a crucial role together with versatile properties (low density, high diffusivity) of water in sub-critical region.

Increase in the current might have increased $\mathrm{H}^{+}$ion concentration due to the increase in potential difference, which resulted in the formation of acid layer around the anode material (Mabbott 1983). The diverse effect of current was more observable at $170{ }^{\circ} \mathrm{C}$ (Fig. 1a) in comparison to $200{ }^{\circ} \mathrm{C}$ (Fig. 1c) since $\mathrm{H}^{+}$concentration was lower at low temperature of reaction. On the contrary, current had positive effect on cellulose conversion at $230{ }^{\circ} \mathrm{C}$ (Fig. 1b). Current might have restricted the formation of the char as a 

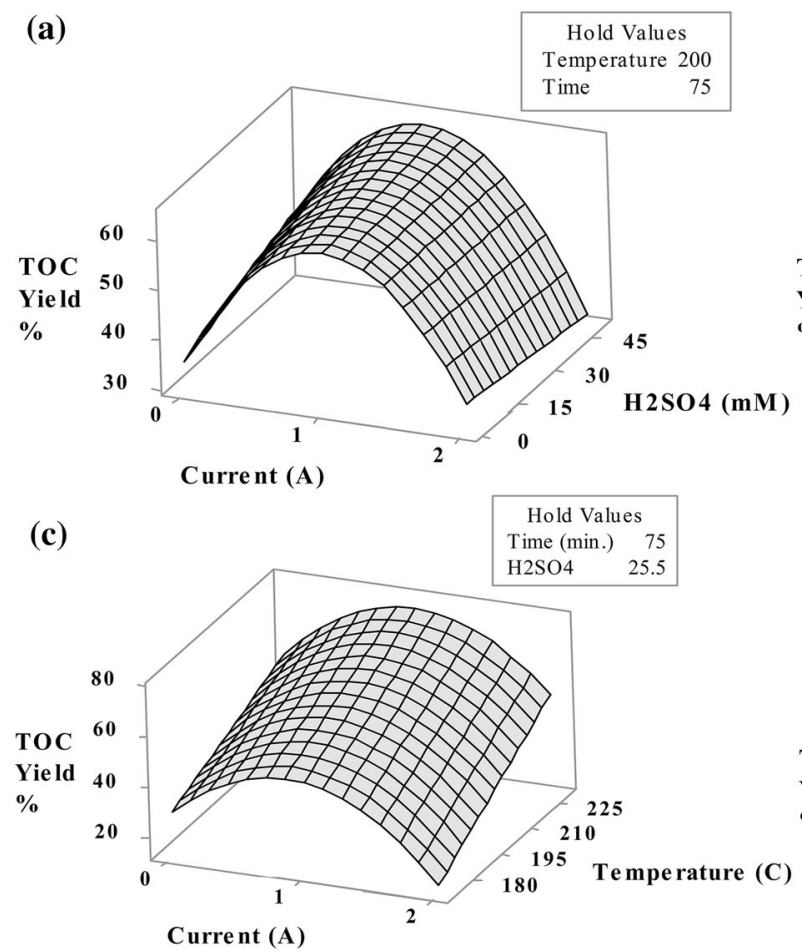
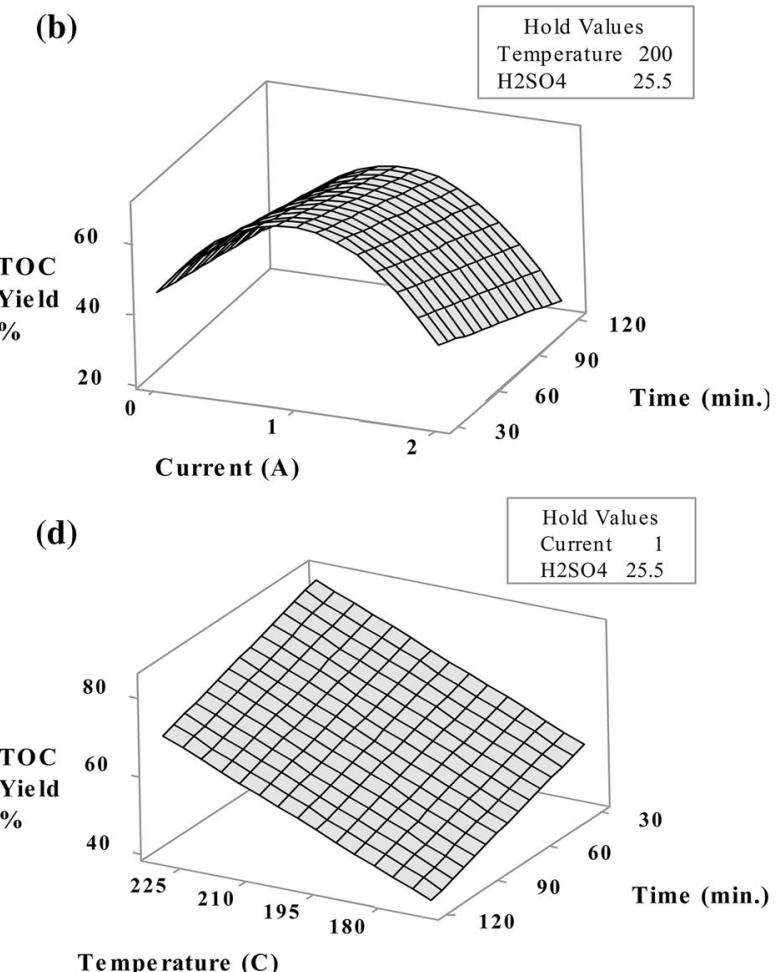

Fig. 5 Surface response plots of total organic content (TOC) with effecting parameters of applied current, reaction temperature and time, acid concentration $\left(\mathrm{H}_{2} \mathrm{SO}_{4}\right)$

result of the polymerization of 5-HMF at higher reaction temperatures (Chuntanapum et al. 2011). Moreover, Fig. 1d indicates that conversion reached its highest value at $200{ }^{\circ} \mathrm{C}$ and decreased at higher reaction temperatures due to formation of char. Additionally, for longer reaction time, conversion started to decrease due to further formation of char molecules (Fig. 1d). Although the mechanism has not been revealed yet, it is possible to say that applied current on the reaction medium at higher temperatures can alter the formation of char (Fig. 3). Moreover, effect of current on char formation may be related to 5-HMF concentration behavior under applied current, which will be discussed in detail in " 5 -HMF, levulinic acid, furfural production" section

TOC conversion, glucose and fructose yields in liquid product

ANOVA test of $(p>0.05)$ TOC conversion showed that the most significant term was temperature followed by reaction time and current applied (Online resource). Quadratic model equation was built with the $\mathrm{R}^{2}$ value of 0.99 and Eq. 4 was evaluated as model equation. The histogram plots of model were analyzed showing that residuals were normally distributed. This indicates that model as applicable, as seen Fig. 4.

$$
\begin{aligned}
\text { TOCConversion }= & -31.280+33.774 A+0.37351 B \\
& -0.11753 C+0.21319 D \\
& -25.908 A * A+0.10524 A \\
& * B-0.03992 A * C-0.14478 A * D
\end{aligned}
$$

Surface response plot (Fig. 5c) of TOC formation indicates that as the temperature increased, TOC conversion increased as well due to the fact that protonation of $\beta(1-4)$ Glycosidic bonds resulted in the formation of decomposition products. However, increase in reaction time had diverse effect on TOC conversion that could be attributed to the formation of char and gas products at longer reaction times during decomposition of cellulose in hot compressed water conditions (Wiedner et al. 2013). Application of current to the reaction medium dramatically 

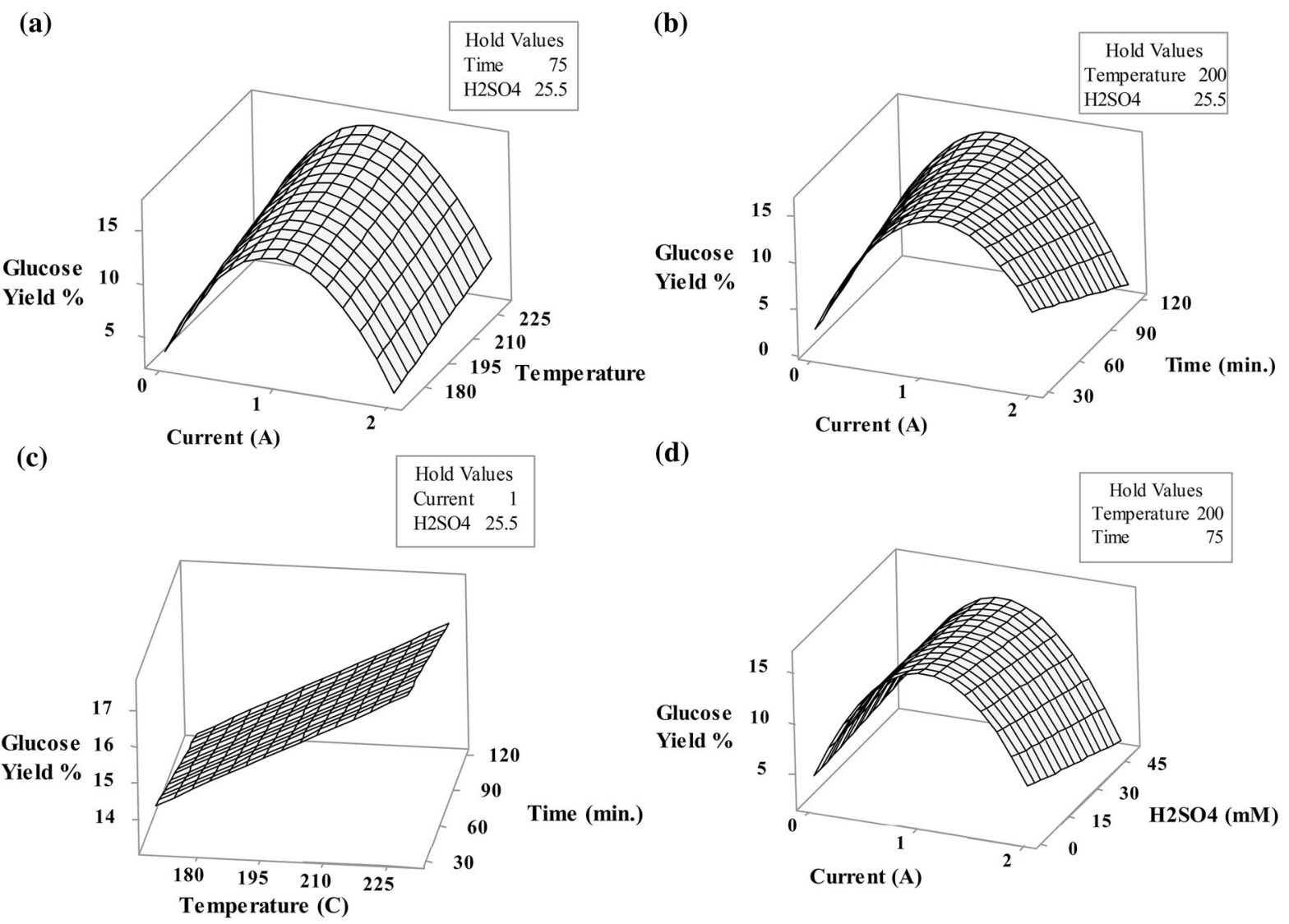

(d)

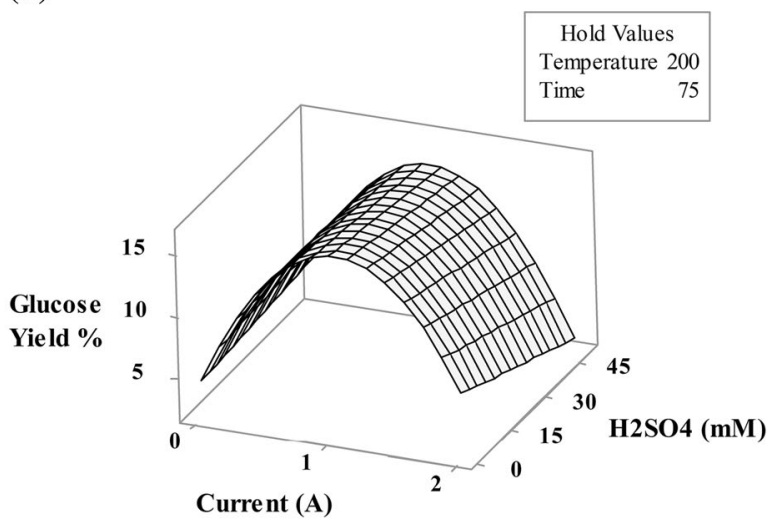

Fig. 6 Surface response plots of glucose yield with effecting parameters of applied current, reaction temperature, time and acid concentration $\left(\mathrm{H}_{2} \mathrm{SO}_{4}\right)$

increased the TOC conversion (Fig. 5a) up to $1 \mathrm{~A}$. However, further increment in current resulted in sharp decrease of TOC conversion. Similar trend was also observed for all reaction temperatures (Fig. 5c). The current effect on TOC conversion at low acid concentration of $1 \mathrm{mM} \mathrm{H}_{2} \mathrm{SO}_{4}$ supported the idea of electrochemically generated acid layer around anode material due to dissociation of water molecules that resulting in the protonation of $\beta(1-4)$ Glycosidic bonds. It was also found that conversion of cellulose was diversely affected by the applied current, which can be attributed to the increase in TOC conversion selectively with direct current passing through the electrodes by limiting the formation of tarry material. 5-HMF formation and SEM images ("Analysis of solid residue" section, Fig. 12c) further supported the formation of tarry material for non-current experiments.

In electrochemical organic synthesis reactions, water as a solvent has a poor potential window; in other words, applied over potential results in the formation of hydrogen and oxygen gases. High potential difference in reaction medium may increase the formation rate of hydrogen gases and hence, protonation reaction rate increases due to the high concentration of $\mathrm{H}^{+}$ions in reaction medium. Therefore, diverse effect on TOC conversion could be due to further reactions involved as a result of high $\mathrm{H}^{+}$ concentration at longer reaction time $(75 \mathrm{~min}$.). Shorter reaction time (30 min) with passing $2 \mathrm{~A}$ current resulted in TOC conversion of $61 \%$ with $1 \mathrm{mM} \mathrm{H}_{2} \mathrm{SO}_{4}$ and at a temperature of $230{ }^{\circ} \mathrm{C}$. On the other hand, the current free experiment at the same conditions except $50 \mathrm{mM} \quad \mathrm{H}_{2} \mathrm{SO}_{4}$ concentration yielded $62 \%$ of TOC conversion (Table 1). Applied current diminished the acid concentration from 50 to $1 \mathrm{mM}$ by keeping the TOC amount constant. It is the evidence of the over potential resulting in the formation of acid layer around anode. The use of model equation for TOC prediction (Eq. 4) by applying $2 \mathrm{~A}$ current at $230{ }^{\circ} \mathrm{C}$ with $1 \mathrm{mM} \mathrm{H}_{2} \mathrm{SO}_{4}$ resulted in $64 \%$ of TOC at reaction time of 10 min while $1 \mathrm{~A}$ current 
increased to $84 \%$. This might be explained by acid formation due to dissociation of water around the anode and increase in the rate of formation of hydrogen gases at higher current values as observed in GC-TCD analysis. Moreover, GC-TCD analysis showed that there was no hydrogen gas formed during 1 A applied current in contrast to $2 \mathrm{~A}$ in which hydrogen gases was formed with a concentration of $95 \mu \mathrm{g} / \mathrm{ml}$ ("Gas products" section, Fig. 11a.)

As well known, cellulose decomposes to the cellobiose and oligosaccharides such as cellotriose, cellopentose as a result of protonation of intra- and inter-molecular hydrogen bonds. Further decomposition resulted in formation of glucose molecules. ANOVA test to glucose yield $(p>0.005)$ showed that all parameters had significant effect as individually; however, interaction term of current with temperature had the $p$ value of 0.713 that was higher than confidence interval. Therefore, it was manually removed from the model and its effect was considered as disturbance in responses and investigated model equation (Eq. 5) was given as follows.

$$
\begin{aligned}
\text { Glucose Yield } \%= & -10.943+27.548 A+0.05569 B \\
& +0.05722 C+0.02143 D \\
& -10.619 A * A-0.06774 A * C \\
& -0.05666 A * D
\end{aligned}
$$

ANOVA results showed that temperature had the highest effect on glucose yield [Online Resource (Table 5)]. Response surface plot of glucose (Fig. 6c) indicates that at low concentration of acid $(1 \mathrm{mM}$ $\mathrm{H}_{2} \mathrm{SO}_{4}$ ), when reaction temperature was increased, glucose concentration also increased from 4 to $9 \%$. At higher reaction temperature, up to $230{ }^{\circ} \mathrm{C}$, dissociation constant, $\mathrm{K}_{\mathrm{w}}$, for water increases (Bignold et al. 1971). Formation of water dissociation products as $\mathrm{H}^{+}$and $\mathrm{OH}^{-}$favor the cellulose decomposition reaction pathway in ionic reaction mechanism (Buhler et al. 2002). Therefore, hydrolysis rate of cellulose increases at higher temperature and yields high concentration of glucose. In acidic conditions, glucose is further involved in the reactions such as isomerization to fructose following the formation of decomposition products such as 5-HMF, levulinic acid, formic acid, and furfural. Hence, glucose yield decreased to $2 \%$ at higher acid concentrations (25 and $50 \mathrm{mM} \mathrm{H}_{2} \mathrm{SO}_{4}$ ). As the ionic reaction mechanism becomes favorable at higher $\mathrm{K}_{\mathrm{w}}$ value of water, applied current to the reaction medium may favor the decomposition pathway in ionic mechanism due to the self-dissociation of water around the anode and cathode. In addition, current had similar effect on glucose yield (Fig. 6a, b, d) as it was in TOC yield. Applied 1 A current on the reaction medium at low temperature $\left(170{ }^{\circ} \mathrm{C}\right)$ increased the glucose yield (13\%) compared to current free experiment (3.2\%). Electrochemical generation of acid layer around anode material could have increased the rate of cellulose decomposition as similar current effect was observed on TOC conversion (Fig. 5a). However, 2 A of current loaded experiments for longer reaction times ( 75 and $120 \mathrm{~min}$.) resulted in lower glucose yield. This could be due to further reactions of glucose such as retroaldol condensation to eryhtrose, glycoaldehyde, and glyceraldehyde (Yin and Tan 2012).

Fructose is produced by isomerization of glucose. Further decomposition and dehydration of fructose resulted in products as furans and carboxylic acids (Promdej and Matsumura 2011). The Lobry de BruynAlberda van Ekensteing (LBAE) transformation of glucose to fructose has been studied by number of researches and found that intermediate products of enediols are produced during this transformation. Retro aldol and reverse aldol condensation of aldehydes yield erthyrose, glycoaldehyde and glyceraldehyde (Kabyemela et al.1999). GC-MS results showed that glycoaldehyde and glyceraldehyde were formed during hydrothermal electrolysis of microcrystalline cellulose. In ionic mechanism, retro aldol condensation of enediols, which is formed during LBAE transformation, yields to the formation of aldehydes. In addition, ANOVA test to fructose yield $(p>0.05)$ showed that temperature and acid concentration were the most significant terms in the model equation (Eq. 6). Fructose formation was effected significantly since the ionic concentration highly depends on the temperature and acid concentration. However, the individual effect of current and reaction time had the p-value of 0.982 and 0.579 , respectively. Therefore current and reaction time had no significant individual effect on the fructose yield. This is due the fact that, an increase in the applied current at low temperature $\left(170{ }^{\circ} \mathrm{C}\right)$ had no significant effect on fructose formation at different reaction times. This could be explained by the lack of reactant such as glucose for the isomerization reaction. Therefore, ANOVA 

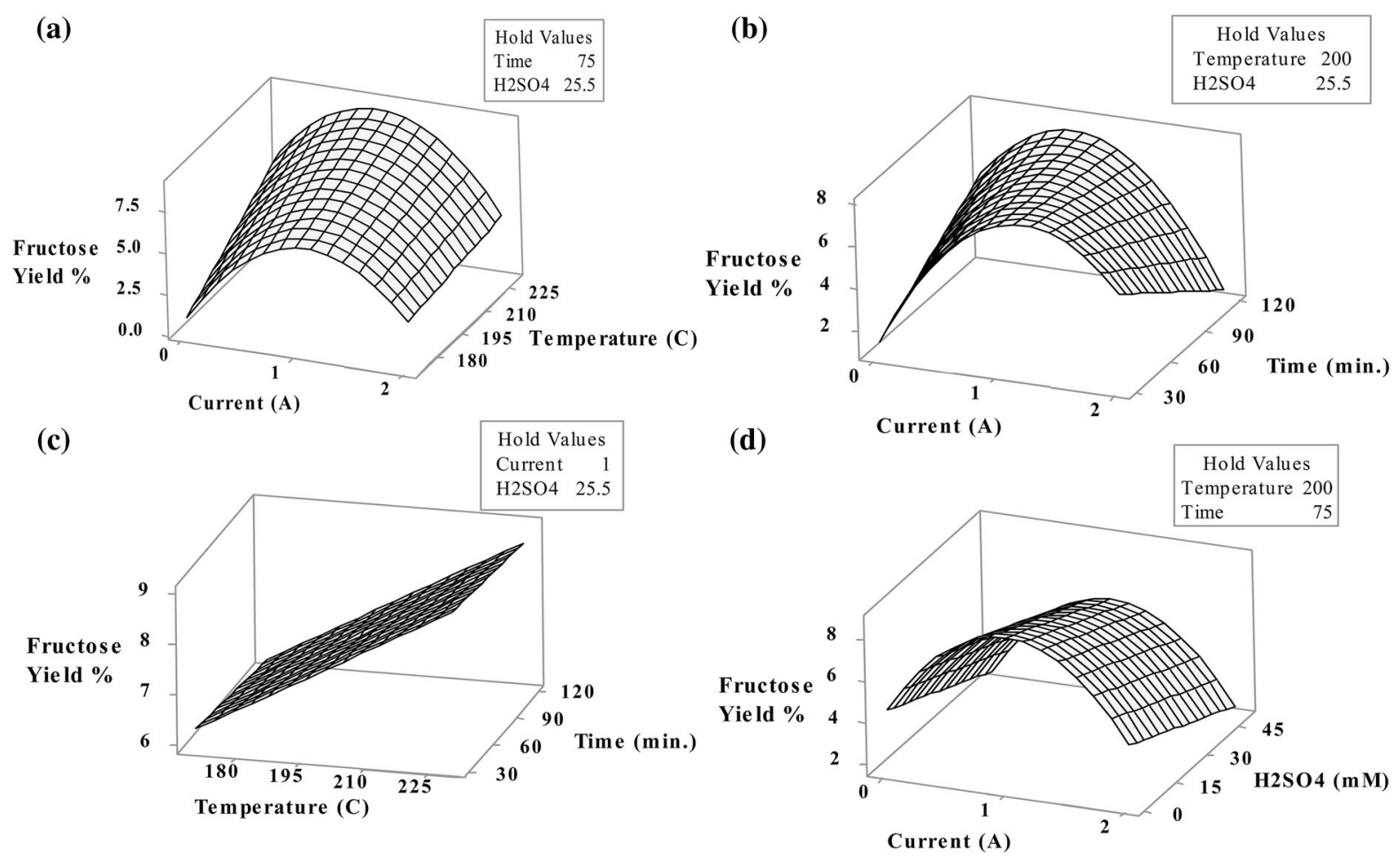

Fig. 7 Surface response plots of fructose yield with effecting parameters of applied current, reaction temperature and time, acid concentration $\left(\mathrm{H}_{2} \mathrm{SO}_{4}\right)$

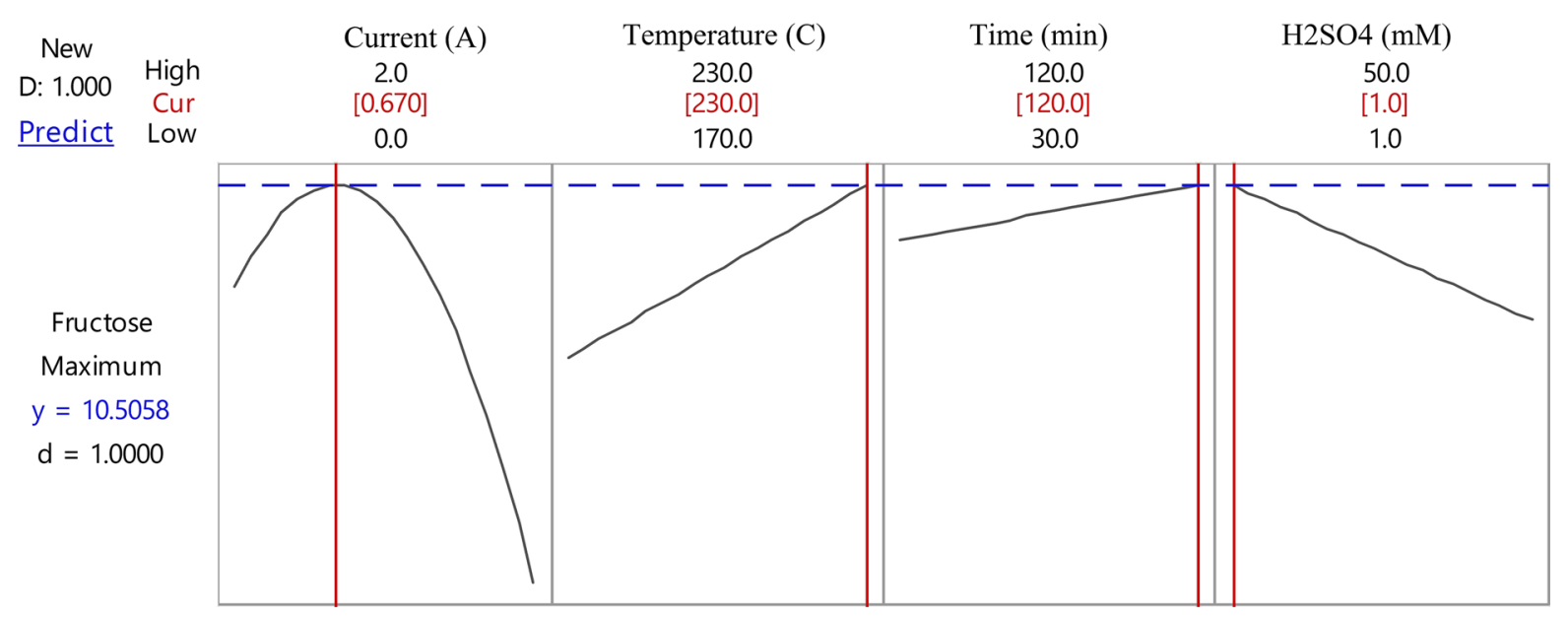

Fig. 8 Predicted operating parameters to maximize fructose yield

showed that current and reaction time had no significant individual effect on fructose formation; however, coupled effect of current and reaction time with reaction temperature and acid concentration resulted in the p-value less than 0.05 indicating that synergetic effect plays an important role in glucose isomerization reaction (Online Resource). As a result, applied current became significant at higher reaction temperatures $\left(200\right.$ and $230{ }^{\circ} \mathrm{C}$ ). At $200{ }^{\circ} \mathrm{C}$ and $1 \mathrm{~A}$ of current, glucose concentration reached its maximum value and was isomerized to fructose due to the higher concentration of reactant. 
Table 4 Statistical analysis results of 5-HMF, levulinic acid and furfural

\begin{tabular}{|c|c|c|c|c|c|c|c|c|c|c|}
\hline \multirow[t]{2}{*}{ Source } & \multicolumn{5}{|c|}{ (5-HMF) } & \multicolumn{5}{|c|}{ Levulinic acid } \\
\hline & $\mathrm{DF}$ & $\begin{array}{l}\text { Sum of } \\
\text { squares }\end{array}$ & $\begin{array}{l}\text { Mean of } \\
\text { squares }\end{array}$ & $\begin{array}{l}\mathrm{F} \\
\text { value }\end{array}$ & $P$ value & DF & $\begin{array}{l}\text { Sum of } \\
\text { squares }\end{array}$ & $\begin{array}{l}\text { Mean of } \\
\text { squares }\end{array}$ & $\mathrm{F}$ value & $P$ value \\
\hline Model & 8 & 105.83 & 13.23 & 238.16 & 0.000 & 8 & 2774.65 & 346.83 & 2508.62 & 0.000 \\
\hline Linear & 4 & 45.96 & 10.74 & 193.34 & 0.000 & 4 & 2275.66 & 568.92 & 4114.95 & 0.000 \\
\hline Current (A) & 1 & 3.37 & 3.37 & 60.62 & 0.000 & 1 & 108.42 & 108.42 & 784.20 & 0.000 \\
\hline Temperature (B) & 1 & 32.83 & 32.83 & 591.09 & 0.000 & 1 & 1278.96 & 1278.96 & 9250.67 & 0.000 \\
\hline Time (C) & 1 & 0.83 & 0.83 & 14.91 & 0.003 & 1 & 15.23 & 15.23 & 110.15 & 0.000 \\
\hline $\mathrm{H}_{2} \mathrm{SO}_{4}$ (D) & 1 & 5.93 & 5.93 & 106.74 & 0.000 & 1 & 873.05 & 873.05 & 6314.79 & 0.000 \\
\hline Square & 1 & 3.28 & 3.28 & 59.02 & 0.000 & 1 & 1.50 & 1.50 & 10.84 & 0.000 \\
\hline Current $\times$ current & 1 & 3.28 & 3.28 & 59.02 & 0.000 & 1 & 1.50 & 1.50 & 10.84 & 0.009 \\
\hline 2-Way interaction & 3 & 59.60 & 19.87 & 357.63 & 0.000 & 3 & 497.49 & 165.83 & 1199.45 & 0.000 \\
\hline Current $\times$ temperature & 1 & 0.60 & 0.60 & 10.81 & 0.008 & 1 & 28.06 & 28.06 & 202.98 & 0.008 \\
\hline Current $\times$ time & 1 & 44.55 & 44.56 & 802.31 & 0.000 & 1 & 464.08 & 464.08 & 3356.68 & 0.000 \\
\hline Current $\times \mathrm{H}_{2} \mathrm{SO}_{4}$ & 1 & 14.44 & 14.44 & 259.96 & 0.000 & 1 & 5.35 & 5.35 & 38.68 & 0.000 \\
\hline Error & 10 & 0.56 & 0.06 & & & 9 & 1.24 & 0.14 & & 0.000 \\
\hline Total & 18 & 10.39 & & & & 17 & 2775.89 & & & \\
\hline \multirow[t]{2}{*}{ Source } & & \multicolumn{9}{|c|}{ Furfural } \\
\hline & & DF & \multicolumn{2}{|c|}{ Sum of squares } & & \multicolumn{2}{|c|}{ Mean of squares } & \multicolumn{2}{|l|}{ F value } & $P$ value \\
\hline Model & & 8 & 12.89 & \multicolumn{4}{|c|}{1.61} & \multicolumn{2}{|l|}{290.99} & 0.000 \\
\hline Linear & & 4 & 9.60 & \multicolumn{4}{|c|}{2.40} & \multicolumn{2}{|l|}{433.68} & 0.000 \\
\hline Current (A) & & 1 & 2.61 & \multicolumn{4}{|c|}{2.61} & \multicolumn{2}{|l|}{471.08} & 0.000 \\
\hline Temperature (B) & & 1 & 6.97 & \multicolumn{4}{|c|}{6.97} & \multicolumn{2}{|l|}{1258.81} & 0.000 \\
\hline Time (C) & & 1 & 0.02 & \multicolumn{4}{|c|}{0.02} & \multicolumn{2}{|l|}{4.06} & 0.000 \\
\hline $\mathrm{H}_{2} \mathrm{SO}_{4}$ (D) & & 1 & 0.00 & \multicolumn{4}{|c|}{0.00} & \multicolumn{2}{|l|}{0.76} & 0.000 \\
\hline Square & & 1 & 0.00 & \multicolumn{4}{|c|}{0.00} & \multicolumn{2}{|l|}{0.49} & 0.000 \\
\hline Current $\times$ current & & 1 & 0.00 & \multicolumn{4}{|c|}{0.00} & \multicolumn{2}{|l|}{0.49} & 0.498 \\
\hline 2-Way interaction & & 3 & 3.28 & \multicolumn{4}{|c|}{1.09} & \multicolumn{2}{|l|}{197.58} & 0.498 \\
\hline Current $\times$ temperature & & 1 & 1.51 & \multicolumn{4}{|c|}{1.51} & \multicolumn{2}{|l|}{273.25} & 0.000 \\
\hline Current $\times$ time & & 1 & 1.30 & & & .30 & & 234.73 & & 0.000 \\
\hline Current $\times \mathrm{H}_{2} \mathrm{SO}_{4}$ & & 1 & 0.47 & & & .47 & & 64.75 & & 0.000 \\
\hline Error & & 10 & 0.06 & & & .02 & & 0.01 & & 0.000 \\
\hline Total & & 18 & 12.94 & & & .055 & & & & \\
\hline
\end{tabular}

$$
\begin{aligned}
\text { Fructose Yield\% }= & -13.58+17.89 A+0.0753 B A \\
& +0.04053 C-0.05311 D \\
& -4.340 A * A-0.02987 A \\
& * B-0.04322 A * C
\end{aligned}
$$

The interaction of current and acid concentration had no significant impact $(p>0.05)$ and therefore removed from the model equation. Response surface plot (Fig. 7a) indicates that current had high interaction with reaction temperature and time (Fig. $7 b$ ). When the process conditions were optimized to maximize fructose yield, Fig. 8 was obtained. The model resulted in $10 \%$ of maximum fructose yield under the conditions of 0.67 A current, reaction temperature as $230{ }^{\circ} \mathrm{C}$, for $120 \mathrm{~min}$ reaction time and with $1 \mathrm{mM} \mathrm{H}_{2} \mathrm{SO}_{4}$. 


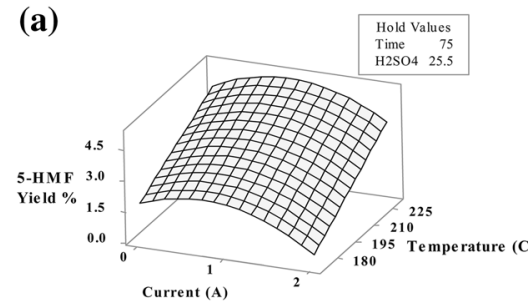

(d)
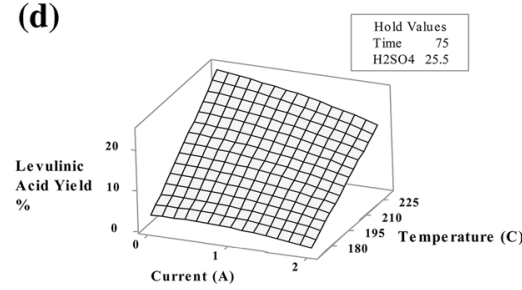

(g)

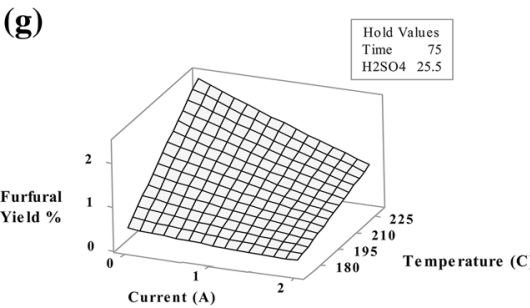

(b)

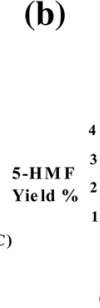

(e)

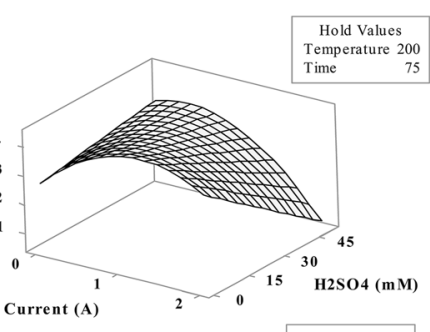

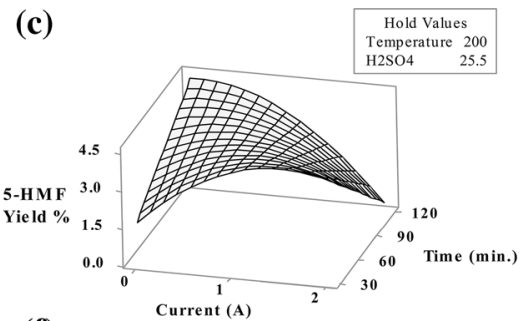

(f)

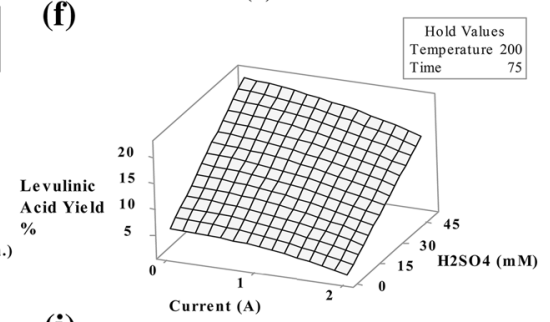

(h)

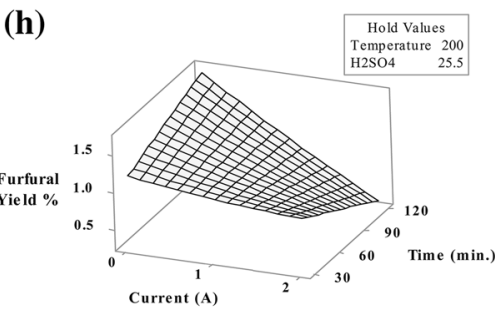

(i)

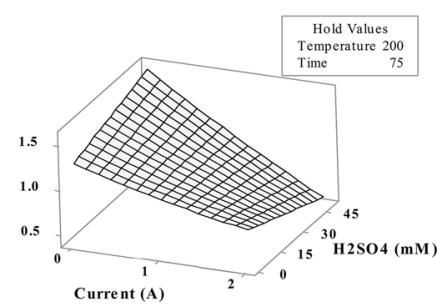

Fig. 9 Surface response plots of 5-HMF, levulinic acid, furfural yields with effecting parameters of applied current, reaction temperature and time, acid concentration $\left(\mathrm{H}_{2} \mathrm{SO}_{4}\right)$

\section{5-HMF, levulinic acid, furfural production}

The conversion of cellulose into HMF involves several reactions including hydrolysis to glucose, isomerization of glucose to fructose, dehydration of fructose to HMF (Antal et al. 1990). Further rehydration of HMF resulted in formation of levulinic acid and formic acid. Furfural is also formed by loss of formaldehyde from 5-HMF. There are two possible pathways of fructose dehydration to HMF. One is the cyclic route by the fructofuranoysl intermediate, and the other one is a cyclic route by enol intermediate (Antal et al. 1990). Antal and coworkers investigated the formation of $\mathrm{HMF}$ from fructose in $\mathrm{H}_{2} \mathrm{SO}_{4}$ catalyzed reaction medium of $\mathrm{D}_{2} \mathrm{O}$ solvent. They did not observed formation of deuterium-carbon in 5-HMF showing that $5-\mathrm{HMF}$ is formed by acyclic mechanism. Acyclic intermediates can be involved dehydration and fragmentation reactions. In this study, intermediate products were not considered since GC-MS and HPLC analysis did not detect significant amount of these products.

From the statistical analysis, following equations (Eqs. 7-9) were obtained to calculate the yields of 5 -HMF, levulinic acid and furfural $(p<0.05)$.

$$
\begin{aligned}
5-\text { HMF Yield } \%= & -7.959+4.298 A+0.04129 B \\
& +0.03203 C+0.01393 D \\
& -1.139 A * A+0.00646 A \\
& * B-0.03708 A * C-0.03878 A * D
\end{aligned}
$$

$$
\begin{aligned}
\text { Furfural Yield\% }= & -5.584+2.234 A+0.032250 B \\
& +0.005500 C+0.00633 D \\
& +0.0329 A * A-0.010250 A * B \\
& -0.006333 A * C-0.006990 A * D
\end{aligned}
$$




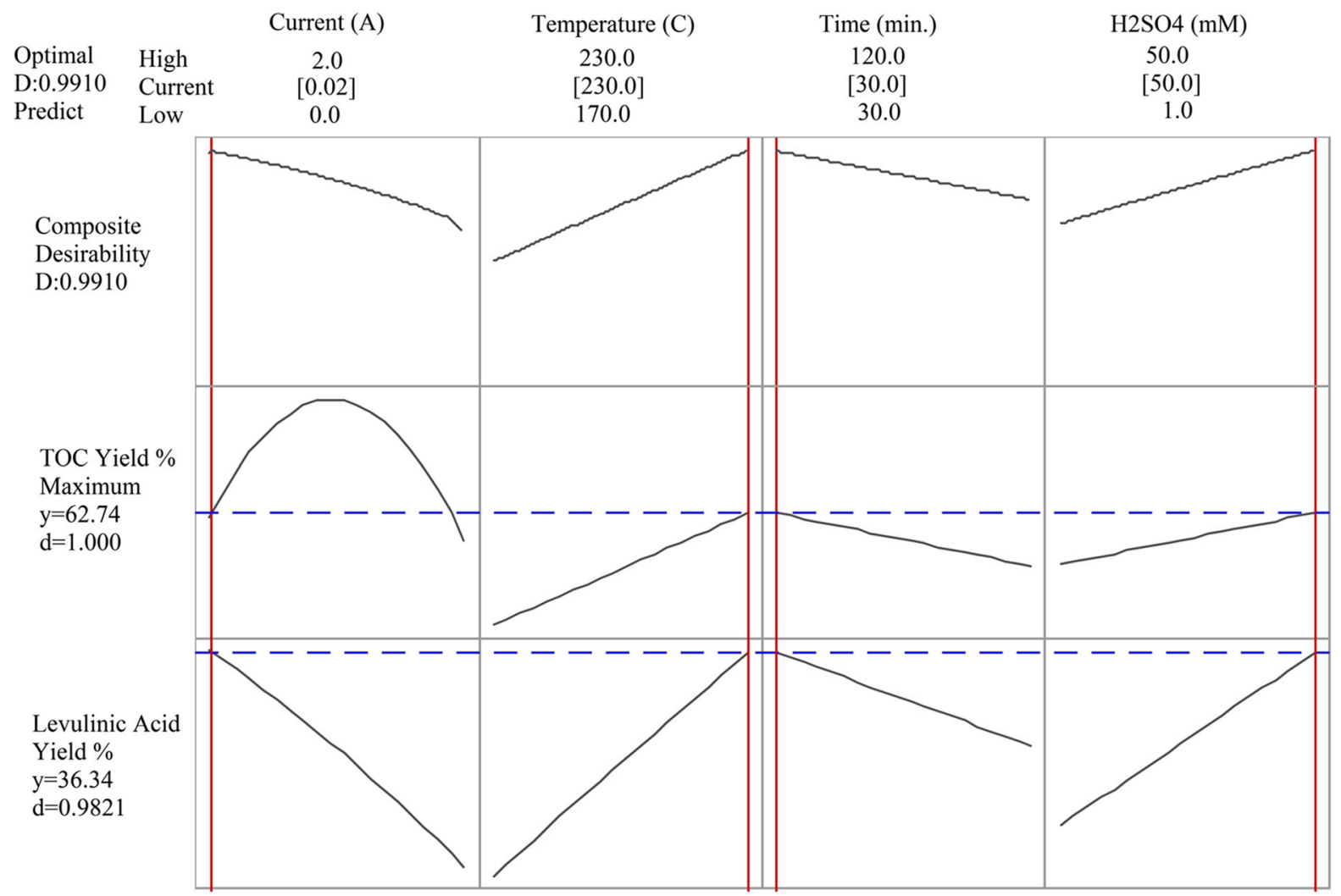

Fig. 10 Optimized parameters for maximum yield of total organic content and levulinic acid

$$
\begin{aligned}
\text { Levulinic Acid Yield\% } \% & -55.513-0.312 A \\
& +0.34217 B-0.09800 C \\
& +0.32510 D-0.918 A \\
& * A-0.04415 A * B \\
& +0.11968 A * C-0.02360 A * D
\end{aligned}
$$

The highest yield of 5-HMF $(7 \%)$ was observed when 2 A current was applied at $230{ }^{\circ} \mathrm{C}$ for 30 min with the

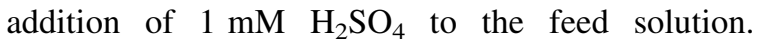
Application of current may limit the side reactions of 5-HMF such as polymerization to tarry materials. It was also observed that total organic carbon in the liquid product solution increased by the application of current to the reaction medium. However, the most significant terms in 5-HMF production were found as temperature and $\mathrm{H}_{2} \mathrm{SO}_{4}$ concentration (Table 4). Response surface plot of 5-HMF yield (Fig. 9b) showed that in current free experiments increase in acid concentration resulted in higher 5-HMF yield. When current was applied after addition of higher acid concentration ( $25 \mathrm{mM}$ and $50 \mathrm{mM} \mathrm{H}_{2} \mathrm{SO}_{4}$ ), diverse effect in which HMF yield was diminished from 6.84 to $3.73 \%$ was observed. This is due to the further rehydration of 5-HMF to levulinic acid and formic acid. Similar behavior was also observed in current and reaction time interaction (Fig. 9c). At 2 A of applied current experiments, 5-HMF yields at $30 \mathrm{~min}$ and $120 \mathrm{~min}$ of reaction time were 5.27 and $1.48 \%$, respectively in contrast with current free experiments, in which reaction time had positive impact on 5-HMF yield; for example $30 \mathrm{~min}$ of reaction time yielded $0.95 \%$, whereas after $120 \mathrm{~min}$ the value reached to $3.83 \%$. This could be due to the formation of acids such as lactic acid, acetic acid and formic acid during the decomposition reaction that changes the ionic constant $\left(\mathrm{K}_{\mathrm{W}}\right)$ of the reaction medium. Effect of current $(2 \mathrm{~A})$ at low reaction time $(30 \mathrm{~min})$ supported the idea of electrochemically generated acidic medium near the anode. Because at $2 \mathrm{~A}$ of applied current, reaction time had diverse effect on 5-HMF concentration (Fig. 9c) in comparison to levulinic acid 

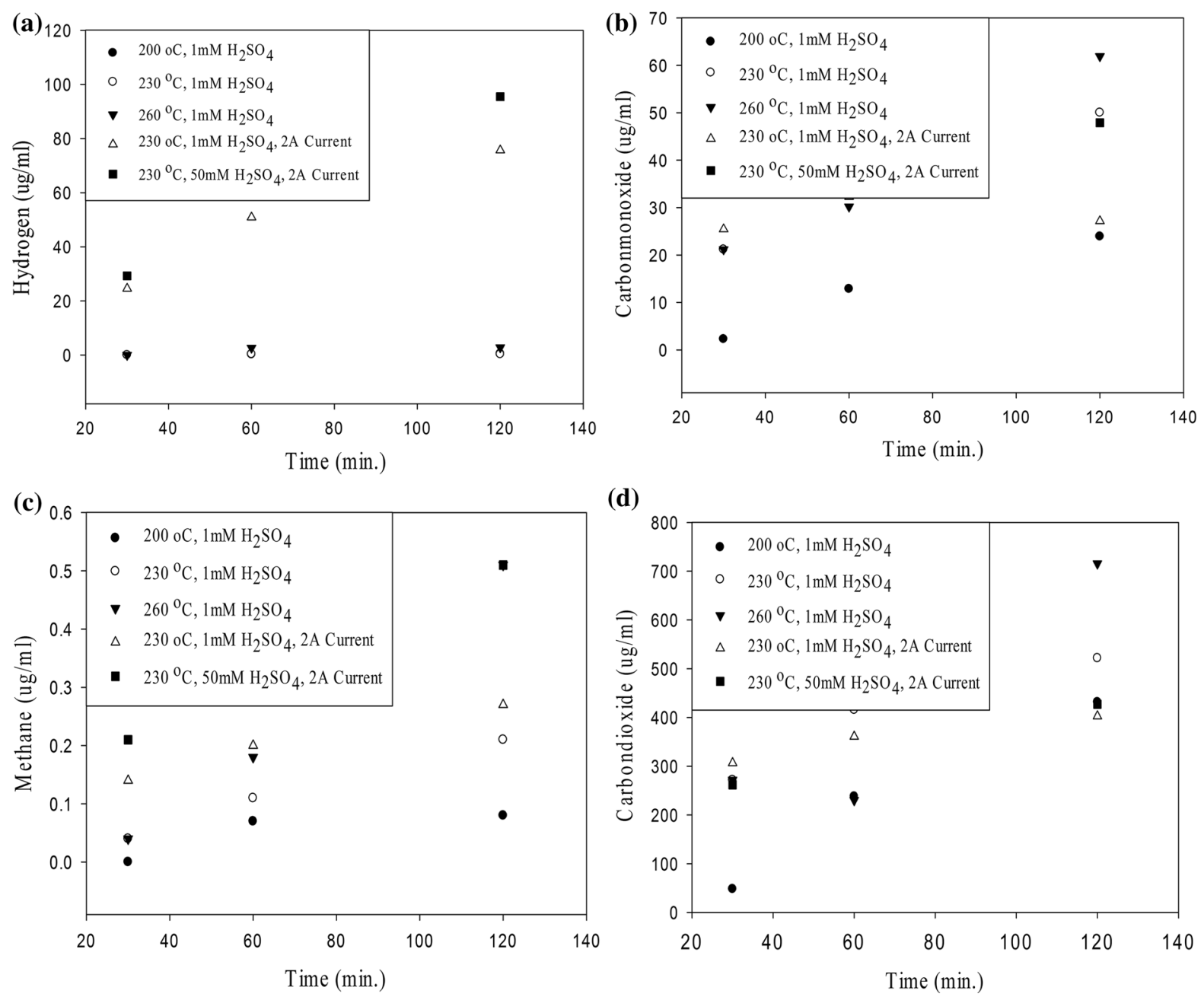

Fig. 11 Formation of gas products a hydrogen, $\mathbf{b}$ carbon monoxide, $\mathbf{c}$ methane, $\mathbf{d}$ carbon dioxide during decomposition of cellulose with the effect of applied current at hot-compressed water at different reaction temperatures

concentration (Fig. 9e). Higher $\mathrm{H}_{2} \mathrm{SO}_{4}$ concentration in applied current experiments resulted in further reactions as rehydration to levulinic acid. Response surface plots of levulinic acid (Fig. 9e) and 5-HMF (Fig. 9c) had the similarity in terms of interaction of applied current and reaction time. Maximum yield of levulinic acid (37\%) was observed without applying current for $30 \mathrm{~min}$ at $230{ }^{\circ} \mathrm{C}$ with the addition of $50 \mathrm{mM} \mathrm{H}_{2} \mathrm{SO}_{4}$. Applied current in this conditions resulted in decrease in the levulinic acid yield to $16 \%$. This decrease in the levulinic acid concentration could be due to restriction of rehydration reaction of 5-HMF under applied current conditions. It was also found that applied current resulted in higher 5-HMF concentration in comparison to current free experiments. Qiu and coworkers (2014) reported that reduction of levulinic acid in acid solution might result in the formation of 4-hydroxypentanoic acid that yields valeric acid. However, GC-MS analysis did not show the formation of valeric acid, hence, diverse effect of current (1 A) on levulinic acid could be related to the formation of 5-HMF. Reaction time had significant interaction with current and its effect on 5-HMF (Fig. 9c) and levulinic acid (Fig. 9e) concentrations changed with applied current. For instance, when reaction time increased (e.g. $120 \mathrm{~min}$.) at $2 \mathrm{~A}$ of current, levulinic acid yield increased from 16 to $28 \%$ and 5-HMF concentration decreased from 4.0 to $0.24 \%$. However, at current free experiments, after 120 min, levulinic acid yield decreased from 18 to 

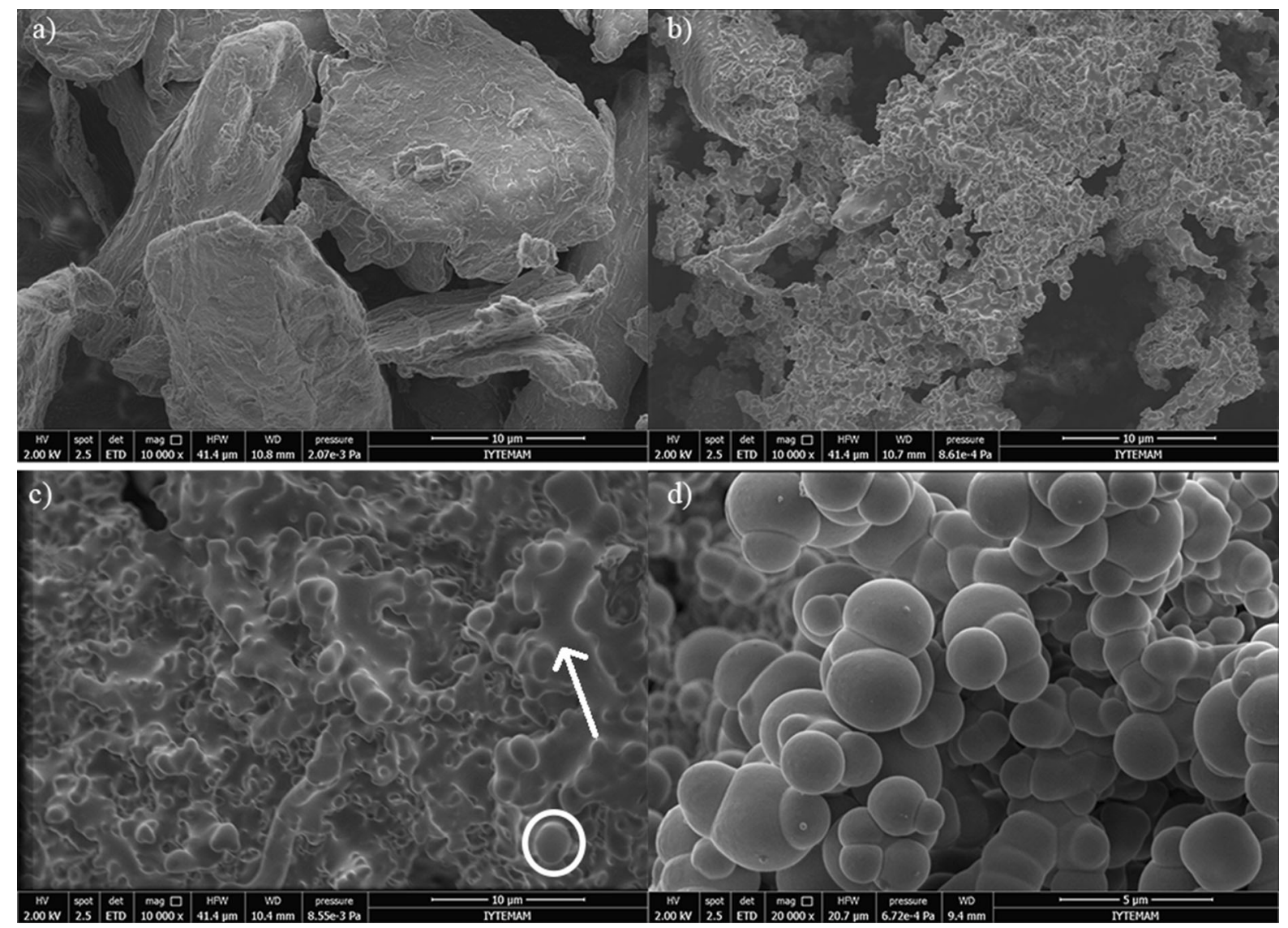

Fig. 12 SEM analysis of a microcrystalline cellulose and solid residues of b $230{ }^{\circ} \mathrm{C}, 0 \mathrm{~A} \mathbf{c} 260{ }^{\circ} \mathrm{C}, 0 \mathrm{~A}$ and $\mathbf{d} 230{ }^{\circ} \mathrm{C}$ after applying $2 \mathrm{~A}$ of current $(a, b$, and $c$ are at magnification of $\times 10,000$ and $d$ is at $\times 20,000)$

$9 \%$ and 5-HMF concentration increased from 1.6 to $4.5 \%$. This replaceable effect of reaction time with current could be due to the change in ionic product concentration, which is affected by electrochemically generated acid layer around anode and formation of degradation products as acids. Figure 10 indicates the optimized parameters to maximize both TOC conversion and levulinic acid yield in the liquid product solution. From this plot, it was predicted that reaction that was carried out with the addition of $50 \mathrm{mM} \mathrm{H}_{2} \mathrm{SO}_{4}$ by passing $0.02 \mathrm{~A}$ current through the electrodes at a reaction temperature of $230{ }^{\circ} \mathrm{C}$ would maximize TOC conversion as $62 \%$ and levulinic acid yield as $36 \%$.

Gas products

Gas samples were collected into plastic bags at sampling times of 30,60 , and $120 \mathrm{~min}$. Collected samples were analyzed by using gas chromatography thermal conductivity detector. Intermediate products of cellulose degradation such as aldehydes and acids can be further decomposed to carbon monoxide and hydrogen gases under hydrothermal conditions. Possible reactions involved in the formation of gas products as $\mathrm{CH}_{4}, \mathrm{C}_{2} \mathrm{H}_{4}, \mathrm{C}_{3} \mathrm{H}_{6}$ reported as the gas products of cellulose decomposition (Gao et al. 2012) are illustrated as follows;

$$
\begin{aligned}
& \mathrm{CO}+\mathrm{H}_{2} \mathrm{O} \leftrightarrow \mathrm{CO}_{2}+\mathrm{H}_{2} \\
& \mathrm{CO}+3 \mathrm{H}_{2} \leftrightarrow \mathrm{CH}_{4}+\mathrm{H}_{2} \mathrm{O} \\
& 2 \mathrm{CO}+\mathrm{H}_{2} \leftrightarrow 1 / 2 \mathrm{C}_{2} \mathrm{H}_{4}+\mathrm{CO}_{2} \\
& 2 \mathrm{CO}+\mathrm{H}_{2} \leftrightarrow 1 / 3 \mathrm{C}_{3} \mathrm{H}_{6}+\mathrm{CO}_{2} \\
& \mathrm{H}_{2} \mathrm{O} \leftrightarrow \mathrm{H}_{2}+1 / 2 \mathrm{O}_{2}
\end{aligned}
$$




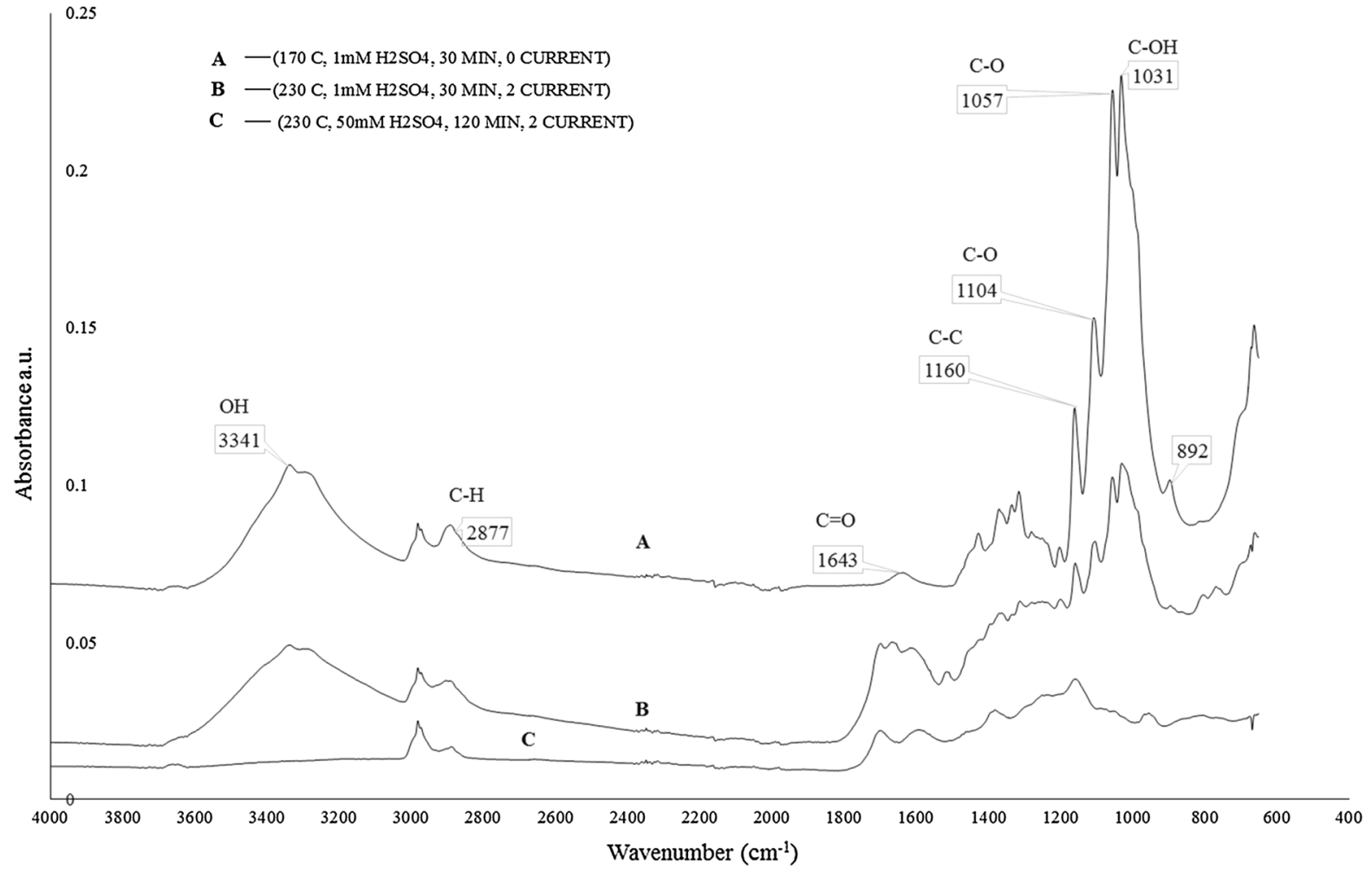

Fig. 13 FTIR spectrum of solid residues at the end of 170 and $230{ }^{\circ} \mathrm{C}$ with 2 A current

Figure 11 indicates the formation of gaseous products during decomposition reaction of MCC under hydrothermal conditions. Gas samples were collected during reaction and at the end of the reaction as the medium cooled down to $50{ }^{\circ} \mathrm{C}$. As the reaction temperature increased from $200{ }^{\circ} \mathrm{C}$ to $260{ }^{\circ} \mathrm{C}$, hydrogen concentration in the gas products increased from 0.52 to $2.83 \mu \mathrm{g} / \mathrm{ml}$ (Fig. 11a) at the sampling time of $120 \mathrm{~min}$. At higher reaction temperatures, water gas shift reaction favors the hydrogen formation. When 2 A current was applied to the reaction medium, hydrogen concentration reached to $53.8(\mu \mathrm{g} / \mathrm{ml})$, as shown in Fig. 11a. However, at 1 A current no hydrogen formation was observed. Higher current value can favor the water electrolysis (Eq. 14) that yields in hydrogen and oxygen production.

An increase in hydrogen gas production may lower the rate of protonation of glycosidic bonds of cellulose. 2A of current applied experiments had lower TOC conversion than the experiments carried out under the influence of $1 \mathrm{~A}$ current. Therefore, applied current in reaction medium changed the reaction mechanism through the formation of TOC instead of gas products and char. When $2 \mathrm{~A}$ current was passed to the reaction medium, the collected gas samples at sampling time of $120 \mathrm{~min}$. and at the end of reaction showed that there was a dramatic decrease in hydrogen gas from 95.48 to $36.71 \mu \mathrm{g} / \mathrm{ml}$ and carbon dioxide gas from 427.14 to $284.83 \mu \mathrm{g} / \mathrm{ml}$ concentrations, respectively. In contrast, carbon monoxide amount increased from 47.89 to $92.24 \mu \mathrm{g} / \mathrm{ml}$. This increase showed that water gas shift reaction (Eq. 10) favored the carbon monoxide side as the reaction temperature cooled from $230{ }^{\circ} \mathrm{C}$ to ambient temperature. Methane formation (Fig. 11c) was also observed and an increment in acid concentration from 1 to $50 \mathrm{mM}$ resulted in 0.27 to $0.51 \mu \mathrm{g} / \mathrm{ml}$, respectively.

Analysis of solid residue

Morphological properties of solid residues at the end of cellulose decomposition reactions in hot-compressed water with and without current were analyzed via SEM. MCC is formed by layers (Fig. 12a) of cellulose chains with the particle size of approximately $30 \mu \mathrm{m}$. Solid residue with $1 \mathrm{mM} \mathrm{H}_{2} \mathrm{SO}_{4}$ at $230{ }^{\circ} \mathrm{C}$ showed that 
cellulose structure was completely destroyed and particles shrunk to lower size (Fig. 12b). At higher temperatures such as $260{ }^{\circ} \mathrm{C}$, when solid residue was monitored by SEM, it was observed that there were solid spheres (circle) formed embedded in tarry materials indicated by an arrow in Fig. 12c. In cellulose degradation, liquid product of 5-HMF can polymerize and forms tarry materials (Chuntanapum et al. 2011). Application of current $\left(2 \mathrm{~A}, 230{ }^{\circ} \mathrm{C}\right)$ to the reaction medium resulted in the formation of carbon spherical particles (Fig. 12d) with particle size of 1-3 $\mu \mathrm{m}$. Clear image of microspheres showed that there was no formation of tarry material around. As it was found from statistical analysis results, applied current to the reaction medium would increase the 5-HMF yield in the product solution and would restrict the formation of tarry materials in the solid residue.

The FTIR spectrum of solid residues is shown in Fig. 13. The peaks at 3341 and $2877 \mathrm{~cm}^{-1}$ are attributed to stretching vibration of $\mathrm{O}-\mathrm{H}$ and $\mathrm{C}-\mathrm{H}$, respectively. The $\mathrm{O}-\mathrm{H}$ stretching vibration at $3341 \mathrm{~cm}^{-1}$ corresponds to intra-molecular hydrogen bond of cellulose. This peak disappeared at $2 \mathrm{~A}$ current and $50 \mathrm{mM} \mathrm{H}_{2} \mathrm{SO}_{4}$ conditions which indicated that intra-molecular hydrogen bonds were protonated and destroyed. Additionally, the peak at $892 \mathrm{~cm}^{-1}$, which is attributed to $\beta$-D-glucopyranosyl, diminished at $230{ }^{\circ} \mathrm{C}$ and $2 \mathrm{~A}$ of current with reaction time of $30 \mathrm{~min}$. This showed that cellulose hydrolysis reaction resulted in destruction of inter-molecular hydrogen bonds (Chung et al. 2004). Moreover, the broad peak from 1530 to $1750 \mathrm{~cm}^{-1}$ shows the existence of aldehydes and ketones absorbed to solid residuals (Gao et al. 2012). This broad spectrum was observed at the residues in which glycosidic bond disappeared. The main characteristic peaks of spectrum 1031 and $1057 \mathrm{~cm}^{-1}$ are assigned as $\mathrm{C}-\mathrm{OH}$ and $\mathrm{C}-\mathrm{O}$ stretching vibrations. The observation of peaks at 1104 and $1160 \mathrm{~cm}^{-1}$ can be attributed to $\mathrm{C}-\mathrm{O}$ and $\mathrm{C}-\mathrm{C}$ stretching vibration of cellulose ether, respectively. These peaks were disappeared in residues obtained at $230{ }^{\circ} \mathrm{C}$, $50 \mathrm{mM} \mathrm{H}_{2} \mathrm{SO}_{4}, 2 \mathrm{~A}$ of current at $120 \mathrm{~min}$. The peak at $1643 \mathrm{~cm}^{-1}$ is assigned as adsorbed water molecules.

\section{Conclusion}

Hydrothermal electrolysis experiments of microcrystalline cellulose were carried out under a wide range of operating parameters by building fractional factorial design. ANOVA test was applied to reveal interaction of applied current with reaction temperature, time and acid concentration. Cellulose conversion reached its maximum value of $82 \%$ at $230{ }^{\circ} \mathrm{C}, 50 \mathrm{mM} \mathrm{H}_{2} \mathrm{SO}_{4}$ and 30 min reaction time. In order to reach the maximum conversion value, application of 1 A current decrease the reaction temperature to $200{ }^{\circ} \mathrm{C}$ and acid concentration to $1 \mathrm{mM}$. Moreover, it was found that $1 \mathrm{~A}$ applied current to the reaction medium at $200{ }^{\circ} \mathrm{C}$ increased the TOC conversion (62\%) by lowering the reaction temperature from 230 to $200{ }^{\circ} \mathrm{C}$ and acid concentration from 50 to $1 \mathrm{mM}$ in comparison with current-free experiments. Effect of current may be explained by the formation of acid layer around the anode material resulting in increased hydrolysis rate of glycosidic bond of oligosaccharides. TOC and GCTCD further supported the idea of electrochemically generated acid layer around anode at lower current values. However, further increase in current (2 A) resulted in decrease of TOC conversion in contrast to an increase in hydrogen production. This can be attributed to increase in hydrolysis reaction rate of water at higher current values.

Levulinic acid concentration reached its maximum yield of $37 \%$ at $230{ }^{\circ} \mathrm{C}$ and with $50 \mathrm{mM}$ acid concentration. With the effect of applied current, levulinic acid concentration decreased from 37 to $13 \%$; however, 5-HMF yield increased to $7 \%$ at $2 \mathrm{~A}$ of current applied experiments. As levulinic acid was produced from 5-HMF, applied current may restrict the 5-HMF decomposition.

Acknowledgments This research is financially supported by Marie Curie Career Integration Grants (FP7-PEOPLE-2012CIG) with a project number of PCIG11-GA-2012-321741. We would like to thank to two research centers at Izmir Institute of Technology for their support in product analysis: "Biotechnology and Bioengineering Research and Application Center" and "Environmental Reference Research and Development Center".

\section{References}

Annamalai N, Rajeswari MV, Balasubramanian T (2014) Enzymatic saccharification of pretreated rice straw by cellulase produced from Bacillus carboniphilus CAS 3 utilizing lignocellulosic wastes through statistical optimization. Biomass Bioenergy 68:151-160 
Antal MJ, Mok WSL, Richards GN (1990) Kinetic-studies of the reactions of ketoses and aldoses in water at high-temperature. 1. mechanism of formation of 5-(hydroxymethyl)-2furaldehyde from D-fructose and sucrose. Carbohyd Res 199:91-109

Asghari FS, Yoshida H (2008) Electrodecomposition in subcritical water using o-xylene as a model for benzene, toluene, ethylbenzene, and xylene pollutants. J Phys Chem A 112:7402-7410

Badgujar KC, Bhanage BM (2016) The green metric evaluation and synthesis of diesel-blend compounds from biomass derived levulinic acid in supercritical carbon dioxide. Biomass Bioenergy 84:12-21

Bignold GJ, Brewer AD, Hearn B (1971) Specific conductivity and ionic product of water between 50 and 271 degrees $C$. Trans Faraday Soc 67(584):2419-2430

Buhler W, Dinjus E, Ederer HJ, Kruse A, Mas C (2002) Ionic reactions and pyrolysis of glycerol as competing reaction pathways in near- and supercritical water. J Supercrit Fluids 22(1):37-53

Chung C, Lee M, Choe EK (2004) Characterization of cotton fabric scouring by FT-IR ATR spectroscopy. Carbohyd Polym 58:417-420

Chuntanapum A, Shii T, Matsumura Y (2011) Acid-catalyzed char formation from 5-HMF in subcritical water. J Chem Eng Jpn 44:431-436

Dinjus E, Kruse A (2004) Hot compressed water-a suitable and sustainable solvent and reaction medium? J Phys-Condens Mat 16:S1161-S1169

Gao Y, Wang XH, Yang HP, Chen HP (2012) Characterization of products from hydrothermal treatments of cellulose. Energy 42:457-465

Kruse A, Dinjus E (2007) Hot compressed water as reaction medium and reactant-Properties and synthesis reactions. J Supercrit Fluid 39:362-380

Kumar S, Kothari U, Kong LZ, Lee YY, Gupta RB (2011) Hydrothermal pretreatment of switchgrass and corn stover for production of ethanol and carbon microspheres. Biomass Bioenergy 35:956-968

Liu CW et al (2015) Aqueous-phase hydrogenolysis of glucose to value-added chemicals and biofuels: A comparative study of active metals. Biomass Bioenergy 72:189-199

Mabbott GA (1983) An introduction to cyclic voltammetry. J Chem Educ 60:697-702

Mante OD, Agblevor FA (2011) Parametric study on the pyrolysis of manure and wood shavings. Biomass Bioenergy 35:4417-4425

Marshall WL, Franck EU (1981) Ion product of water substance, O-degrees-C-1000-degrees-C, 1-10,000 Bars-new international formulation and its background. J Phys Chem Ref Data 10:295-304

Muranaka Y, Suzuki T, Sawanishi H, Hasegawa I, Mae K (2014) Effective production of levulinic acid from biomass through pretreatment using phosphoric acid hydrochloric acid, or ionic liquid. Ind Eng Chem Res 53:11611-11621

Promdej C, Matsumura Y (2011) Temperature effect on hydrothermal decomposition of glucose in sub- and supercritical water. Ind Eng Chem Res 50:8492-8497

Qiu Y, Xin L, Chadderdon DJ, Qi J, Liang CH, Li WZ (2014) Integrated electrocatalytic processing of levulinic acid and formic acid to produce biofuel intermediate valeric acid. Green Chem 16(3):1305-1315

Reddy SN, Nanda S, Dalai AK, Kozinski JA (2014) Supercritical water gasification of biomass for hydrogen production. Int J Hydrogen Energy 39:6912-6926

Saito T, Sasaki M, Kawanabe H, Yoshino Y, Goto M (2009) Subcritical water reaction behavior of D-glucose as a model compound for biomass using two different continuous-flow reactor configurations. Chem Eng Technol 32:527-533

Sasaki M, Yamamoto K, Goto M (2007) Reaction mechanism and pathway for the hydrothermal electrolysis of organic compounds. J Mater Cycles Waste 9:40-46

Sasaki M, Wahyudiono Yuksel A, Goto M (2010) Applications of hydrothermal electrolysis for conversion of 1-butanol in wastewater treatment. Fuel Process Technol 91:1125-1132

Wiedner K, Rumpel C, Steiner C, Pozzi A, Maas R, Glaser B (2013) Chemical evaluation of chars produced by thermochemical conversion (gasification, pyrolysis and hydrothermal carbonization) of agro-industrial biomass on a commercial scale. Biomass Bioenergy 59:264-278

Wu YY, Fu ZH, Yin DL, Xu Q, Liu FL, Lu CL, Mao LQ (2010) Microwave-assisted hydrolysis of crystalline cellulose catalyzed by biomass char sulfonic acids. Green Chem 12:696-700

Yan XY, Jin FM, Tohji K, Kishita A, Enomoto H (2010) Hydrothermal conversion of carbohydrate biomass to lactic acid. AIChE J 56:2727-2733

Yin SD, Tan ZC (2012) Hydrothermal liquefaction of cellulose to bio-oil under acidic, neutral and alkaline conditions. Appl Energ 92:234-239

Yuksel A, Koga H, Sasaki M, Goto M (2010) Hydrothermal electrolysis of glycerol using a continuous flow reactor. Ind Eng Chem Res 49:1520-1525

$\mathrm{Zi}$ GL et al (2015) Catalytic hydrothermal conversion of carboxymethyl cellulose to value-added chemicals over metal-organic framework MIL-53(Al). Carbohyd Polym 115:146-151 